\title{
MANAGEMENT OF ENDOCRINE DISEASE
}

\section{Non-alcoholic fatty liver disease:}

\section{a multidisciplinary approach towards a cardiometabolic liver disease}

\author{
Merel M Ruissen ${ }^{1, *}$, Anne Linde Mak ${ }^{2, *}$, Ulrich Beuers ${ }^{3}$, Maarten E Tushuizen ${ }^{4}$ and Adriaan G Holleboom² \\ ${ }^{1}$ Department of Endocrinology, Leiden University Medical Center, Leiden, the Netherlands, ${ }^{2}$ Department of Vascular \\ Medicine, Amsterdam University Medical Center, Amsterdam, the Netherlands, ${ }^{3}$ Department of Gastroenterology \\ and Hepatology, Amsterdam University Medical Center, Amsterdam, the Netherlands, and ${ }^{4}$ Department of \\ Gastroenterology and Hepatology, Leiden University Medical Center, Leiden, the Netherlands \\ *(M M Ruissen and A L Mak contributed equally to this work and are joint first authors)
}

Correspondence should be addressed to $\mathrm{M}$ E Tushuizen Email

m.e.tushuizen@lumc.nl

\begin{abstract}
Non-alcoholic fatty liver disease (NAFLD) is a growing health problem with a global prevalence of over $25 \%$ and prevalence rates of over $60 \%$ in high-risk populations. It is considered the hepatic component of the metabolic syndrome and is associated with an increased risk of the development of various liver-associated and cardiometabolic complications. Given the complexity of NAFLD and associated comorbidities and complications, treatment requires interventions from a variety of different healthcare specialties. However, many clinicians are currently insufficiently aware of the potential harm and severity of NAFLD and associated comorbidities, complications and the steps that should be taken when NAFLD is suspected. Recognizing which patients suffer from non-progressive simple steatosis, metabolically active NASH with high risk of developing cardiovascular disease and which patients have a high risk of developing cirrhosis and hepatocellular carcinoma is important. Unfortunately, this can be difficult and guidelines towards the optimal diagnostic and therapeutic approach are ambivalent. Here we review the pathogenesis, diagnostics and treatment of NAFLD and discuss how multidisciplinary care path development could move forward.
\end{abstract}

\section{Introduction}

Worldwide, the amount of people leading a so-called 'Western lifestyle', an unhealthy high-caloric diet and only little exercise, has increased tremendously. Associated with this 'Western lifestyle' are obesity and the metabolic syndrome, a term used for the coexistence of an increased abdominal fat mass, hyperglycaemia, hypertension and dyslipidaemia. Non-alcoholic fatty liver disease (NAFLD) is considered to be the hepatic component of metabolic syndrome $(1,2)$. NAFLD is defined by accumulation of intracellular fat in $>5 \%$ of hepatocytes on imaging or histology, in the absence of other causes of hepatic steatosis such as excessive alcohol intake, certain metabolic conditions or drug use (3).

In concert with the increase in prevalence rates of obesity and metabolic syndrome, the prevalence of NAFLD has increased dramatically to over $25 \%$ of the population worldwide (4). In high-risk populations, like patients with type 2 diabetes mellitus (T2DM), prevalence rates are even estimated to be over $60 \%$ (5). The high prevalence of NAFLD and the associated complications and comorbidities, including T2DM and cardiovascular disease, result in a large burden on healthcare, associated 
costs, a reduction of quality of life and increased mortality rates $(3,6,7,8)$.

NAFLD encompasses a spectrum of disease stages. It varies from simple hepatic steatosis, also known as nonalcoholic fatty liver (NAFL), to steatohepatitis (NASH) and development of fibrosis and can eventually progress to cirrhosis and hepatocellular carcinoma (HCC) (Fig. 1) (6). Although NAFLD is very common, only a part of the patients with hepatic steatosis will develop advanced stage liver disease. However, when NAFLD progresses to a more severe liver disease, potential lethal complications like ascites, oesophageal varices, hepatic encephalopathy, HCC and liver failure may arise. It is important to differentiate between patients with non-progressive simple steatosis and patients with metabolically active NASH with high risk of developing cardiovascular disease or those with an increased risk of developing cirrhosis and HCC. Unfortunately, recognizing these at-risk patients can be difficult and guidelines on the optimal diagnostic and therapeutic approach are ambivalent. As a result, many clinicians are currently insufficiently aware of the steps that should be taken when NAFLD is suspected or newly diagnosed. A fundamental aspect of this problem is the paucity of a common healthcare path for NAFLD covering the complexity and multidisciplinary character of this potential harmful disease (9).
Here we review the pathogenesis, diagnostics and treatment of NAFLD and aim to provide a clear overview of the diagnostic options, clinical care strategies and recommendations for the development of a multidisciplinary care path.

\section{Pathogenesis}

The pathogenesis of NAFLD is complex. We give a graphical overview in Fig. 2. For extensive detail, we refer to excellent recent reviews $(2,4,10)$.

In brief, an interaction of environmental factors, diet and genetics results in alterations of multiple factors and pathways of glucose and lipid metabolism that constitute vicious circles, leading to progressive stages of NAFLD. Centrally stands insulin resistance, which causes an increased flux of circulating free fatty acids (FFAs) to the liver, through reduced insulin-mediated suppression of lipolysis in adipose tissue $(11,12,13)$. These FFAs are stored as triglycerides in lipid droplets, reducing hepatic insulin sensitivity and consequently increasing hepatic gluconeogenesis, which results in hyperglycaemia and intrahepatic conversion of glucose to FFAs (14). Meanwhile, high plasma insulin levels increase de novo lipogenesis, producing even more triglycerides and further

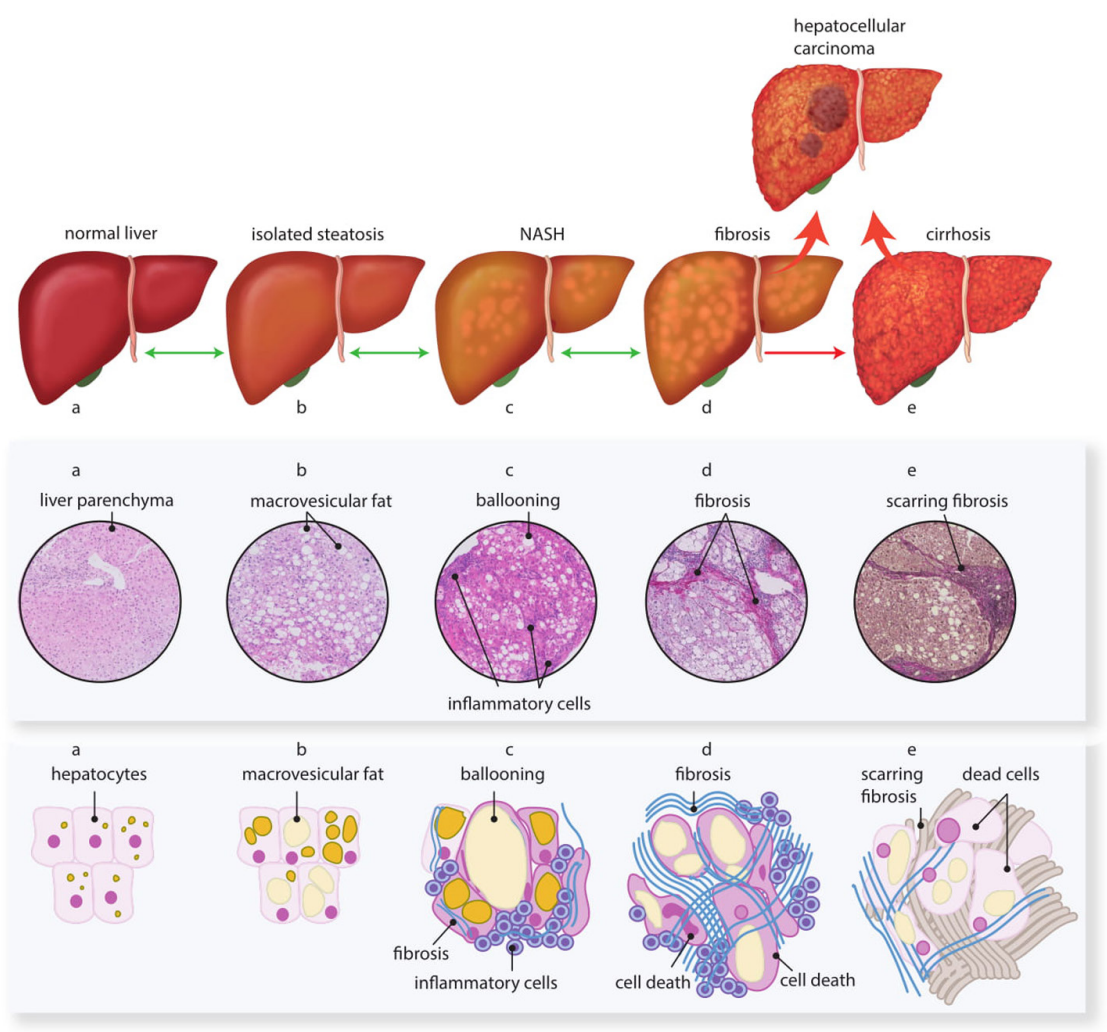

Figure 1

The disease spectrum of non-alcoholic fatty liver disease (NAFLD). 


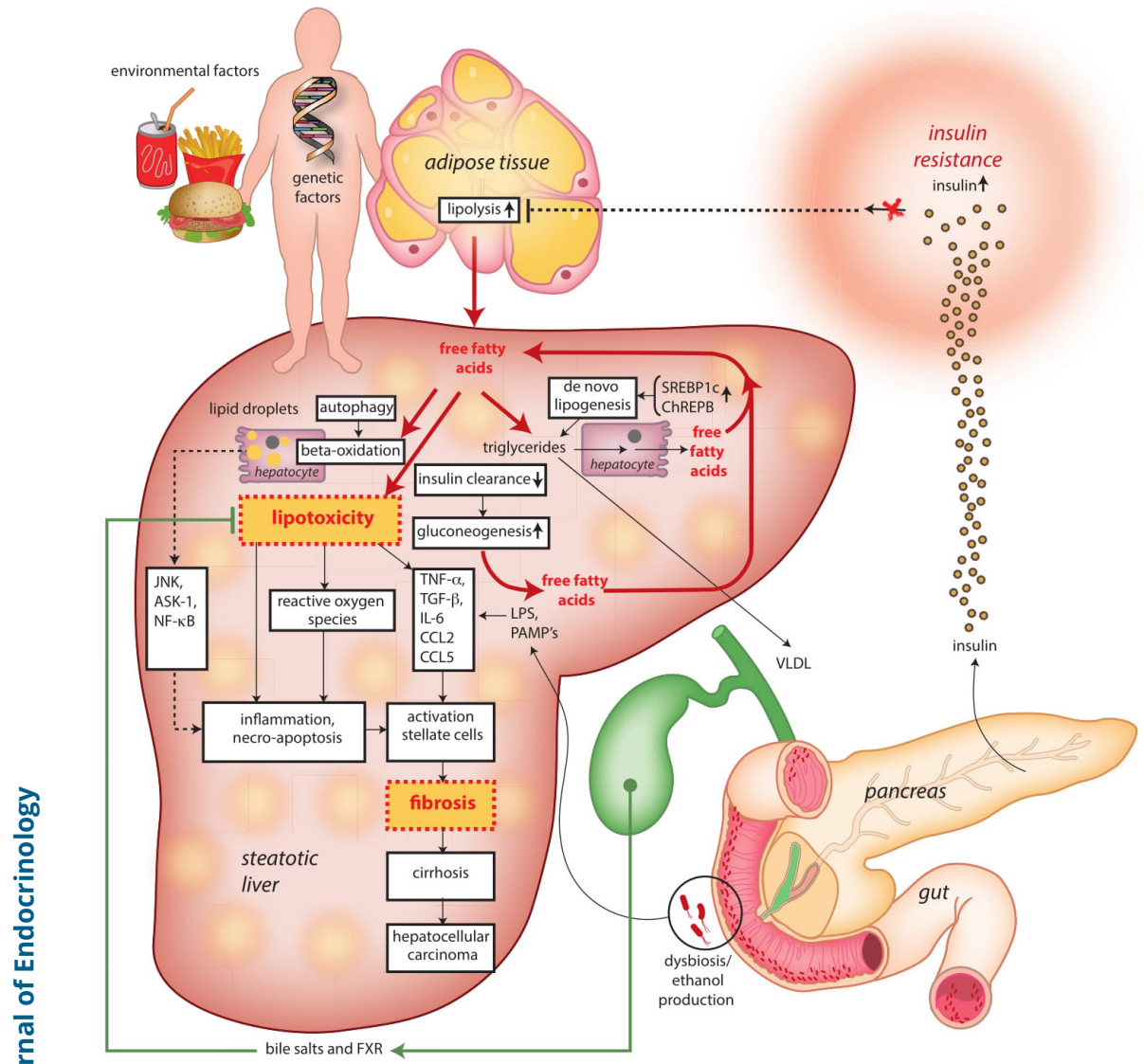

\section{Figure 2}

The pathogenesis of non-alcoholic fatty liver disease (NAFLD).

enhancing hepatic gluconeogenesis. As shown in Fig. 2, this cycle of processes causes an abundance of FFAs and triglycerides. When hepatic compensatory mechanisms fall short, lipotoxicity occurs, causing mitochondrial dysfunction, resulting in formation of reactive oxygen species (oxidative stress), inflammation and cell damage $(15,16,17)$.

The overload of circulating FFAs triggers proinflammatory pathways (c-jun terminal kinase (JNK) via apoptosis signal-regulating kinase 1 (ASK-1), and nuclear factor kappa-light-chain-enhancer of activated B-cells (NF-kB)), leading to inflammation, fibrosis and hepatocyte cell death or apoptosis $(18,19)$. Another pro-inflammatory pathway in NAFLD is formed by the production of cytokines by the visceral fat tissue, the so-called adipocytokines, such as IL- 6 and TNF- $\alpha$. These adipocytokines are directly transported to the liver through the portal system and cause a pro-inflammatory hepatic environment $(18,20$, $21)$, resulting in activation of Kupffer and stellate cells and leading to fibrosis $(22,23,24)$. Various other hepatokines have been shown to play a role in the development of NAFLD-NASH, as reviewed elsewhere (25).

Furthermore, dysregulation of the urea cycle may be involved in the pathogenesis of NAFLD, causing a build-up of toxic ammonia, potentially as a result of mitochondrial dysfunction (26). Many other factors have been implicated in the pathogenesis of NAFLD, including bile acid signalling and the gut microbiome $(27,28)$.

With respect to genetics, variations in genes involved in lipid metabolism and VLDL export (i.e. PNPLA3, TM6SF2, MBOAT7 and HSD17B13) have been found to exert an effect on the complex pathophysiologic mechanisms involved in the development of NAFLD and NASH $(29,30,31,32)$.

\section{Diagnostics}

There is a clear need for good diagnostic tests for NAFLD-NASH. The limited sensitivity of available tests (liver enzymes and ultrasound), as well as the limited implementation of more sensitive diagnostic modalities such as the Fibrosis-4 (FIB-4) score and vibration controlled transient elastography (VCTE), have turned this into a very active development area of the NAFLD research field, with a variety of diagnostic tests available and in development. The performance of diagnostic tests is linked to the prevalence within the tested population and 
therefore, different tests should be used in primary care versus secondary or tertiary care and test results should be interpreted accordingly. Table 1 shows an overview of available tests, their contexts of use, costs, accuracy and (dis)advantages.

Most patients with NAFLD express (slightly) elevated serum liver enzymes, in particular ALT and $\gamma$ GT. However, liver enzymes within the reference range do not exclude NAFLD, and although elevated liver enzymes may serve as a diagnostic clue for the presence of liver disease, they fail to predict the presence and severity of hepatic steatosis, inflammation (NASH) and fibrosis (33). Therefore, various scores have been developed to estimate these aspects of NAFLD in a non-invasive way, such as the Fatty Liver Index (FLI) for steatosis (34) and the FIB-4 score for fibrosis (35).

FLI is an algorithm that combines BMI, waist circumference, $\gamma \mathrm{GT}$ and triglyceride levels to predict the presence of hepatic steatosis with good accuracy as compared to MR or spectroscopy (36). However, it does not identify patients with more advanced disease (NASH or advanced fibrosis). Therefore, FLI is a useful tool in epidemiological studies, but it is not considered useful in a clinical setting (37).

The FIB-4 score is a calculative score based on age, AST and ALT levels and platelet count. It can be used to distinguish patients likely to have advanced fibrosis from those who do not, while keeping in mind the predictive value of the test for the specific patient at the chosen threshold (38). This test recently performed well in a care path in the United Kingdom and guides referral of patients to secondary health care for further analysis and surveillance for cirrhosis associated diseases including oesophageal varices and HCC.

The NAFLD fibrosis score (NFS) is a calculative score that takes into account an impaired fasting glucose or diabetes, age, AST and ALT, platelet count, BMI and albumin. This score performs similarly to FIB-4 for ruling out advanced fibrosis (39).

Another test aimed at identifying patients with liver fibrosis is the Enhanced Liver Fibrosis (ELF) test. This test combines three serum markers of hepatic matrix metabolism: hyaluronic acid, pro-collagen III amino terminal peptide (PIIINP) and tissue inhibitor of metalloproteinase-1 (TIMP-1) and therefore more closely represents the biological process of fibrosis formation (40). It can also be used to monitor disease progression and response to treatment.

Thus far, no non-invasive biomarker or score exists that has both high sensitivity and specificity and is applicable to a wide population of patients and the search for such a marker is on-going. A plethora of biomarkers and scores are currently being tested and validated in large-scale European (LITMUS) (41) and American (NIMBLE) NAFLD biobank studies $(35,39,42)$.

Ultrasonography, in which the reflection pattern of the liver is compared with the kidneys and/or spleen, is a tool often used to determine the presence and extent of hepatic steatosis (43). This diagnostic test is widely available (especially in primary care) and of low cost, although its sensitivity is limited in patients with moderate steatosis $(<20 \%)$ and in those with a BMI $>40 \mathrm{~kg} / \mathrm{m}^{2}(44)$. Furthermore, ultrasonography cannot determine the presence and extent of inflammation (NASH) and fibrosis. Therefore, it can be used to rule out other causes of abnormal liver function tests, but it is not sufficient to be used for risk-stratification or to guide referral of patients suspected of NASH or fibrosis.

'Vibration controlled' transient elastography, VCTE ${ }^{\mathrm{TM}}$ or FibroScan ${ }^{\circledR}$ (brand name) is a non-invasive tool that can be used to measure the elasticity of the liver, thereby determining the presence and extent of fibrosis (45). This technique uses the simultaneous emission of both sonographic and electrical waves. Using the velocity of wave transmission through the tissue, it estimates liver elasticity: the faster the wave, the stiffer the tissue, as in fibrosis. By also using the extinguishment of the ultrasonography signal (the so called continued attenuation parameter, or $\mathrm{CAP}^{\mathrm{TM}}$ ), it estimates the amount of hepatic steatosis. VCTE/CAP was recently shown to be very accurate for both steatosis and cirrhosis over the incremental stages of NAFLD (45). Combined with its ease of use, we therefore expect the application of VCTE/ CAP to increase in both primary and secondary care over the next few years, although the significant cost of the equipment may hamper this development.

The most accurate non-invasive method to diagnose and quantify hepatic steatosis is magnetic resonance imaging (MRI), especially using the so-called proton density fat fraction (PDFF) technique (46). Recently, a new multiparametric MR index has been proposed for diagnosing NASH, in which MR spectrography (MRS), MR elastography (MRE) and T1 mapping were combined in order to cover the various components of NASH. In a small group of $20 \mathrm{NASH}$ and 27 non-NASH patients, this multiparametric MR index was shown to have an AUC of 0.883 , which needs to be validated in larger NAFLD cohorts (47). However, because magnetic resonance imaging is time-consuming, expensive, of limited availability and its validity to measure fibrosis has not yet been confirmed, it is currently less suited for clinical use. 

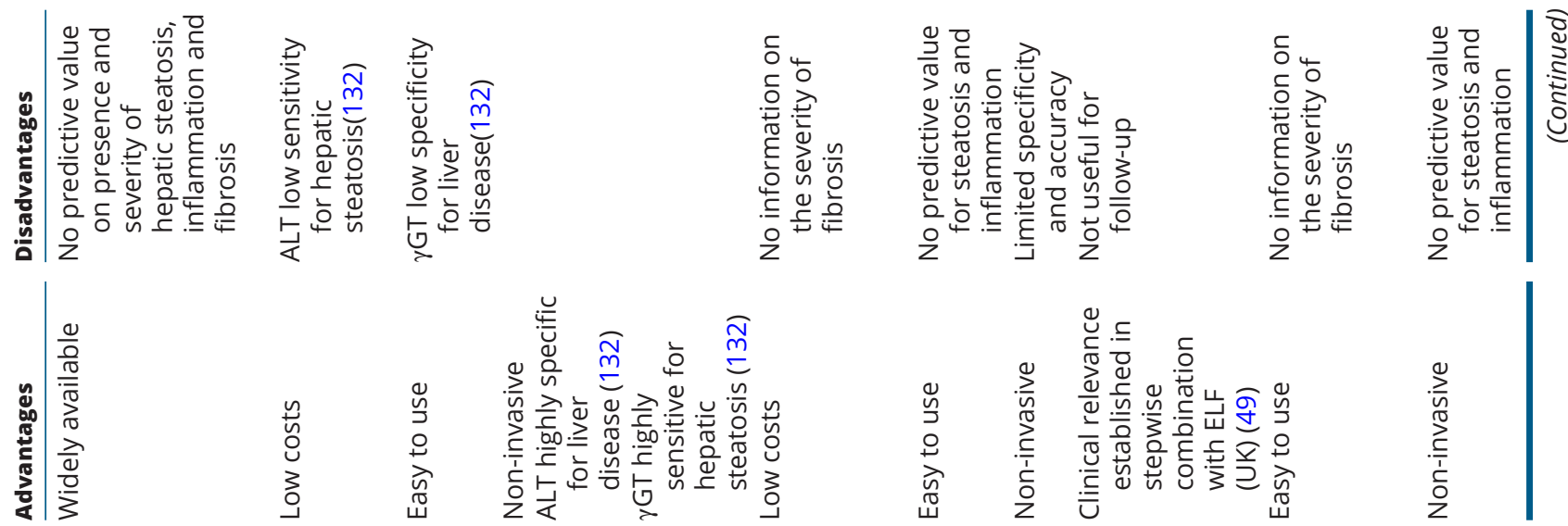

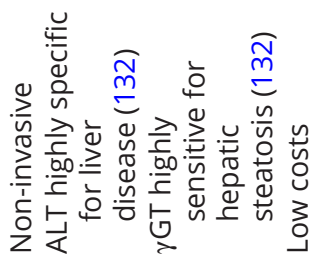

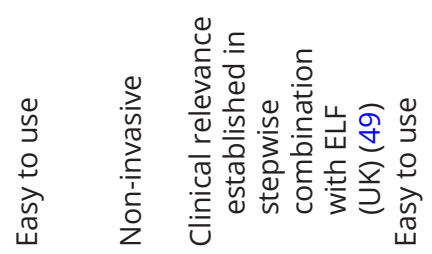

2
$\frac{1}{n}$
$\frac{1}{1}$
$\frac{1}{1}$
$\frac{1}{2}$
$\frac{1}{2}$

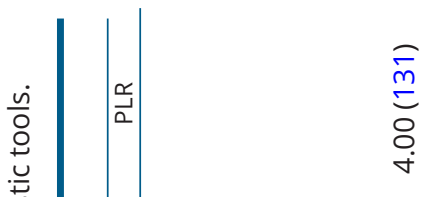

$\stackrel{n}{m}$
$\stackrel{0}{\circ}$
$\stackrel{n}{\sim}$

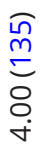

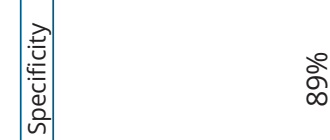

จำ

$\stackrel{\circ}{n}$

o̊ำ

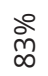

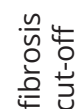

茎商示

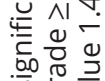

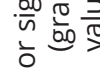
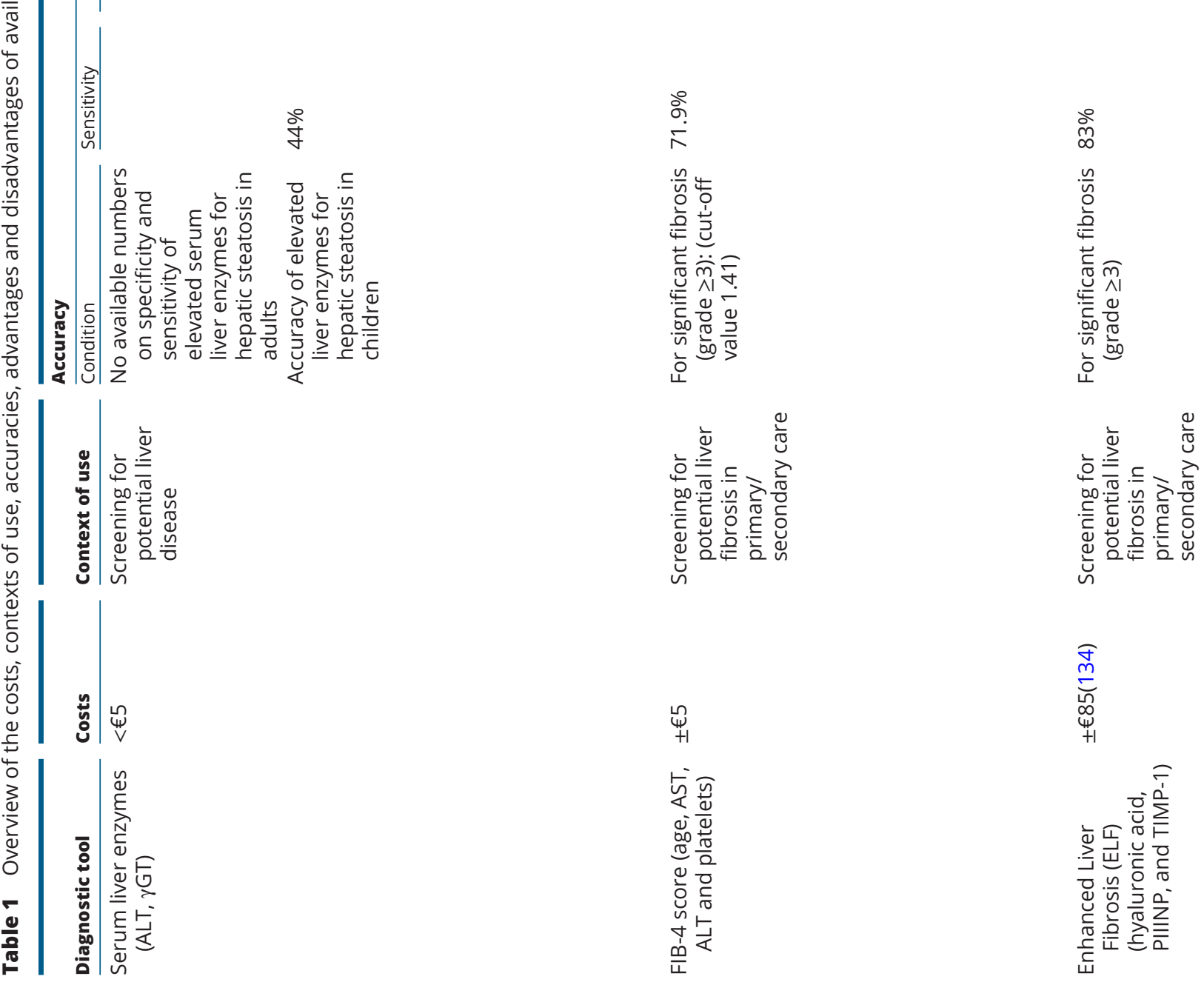

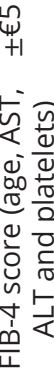

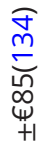
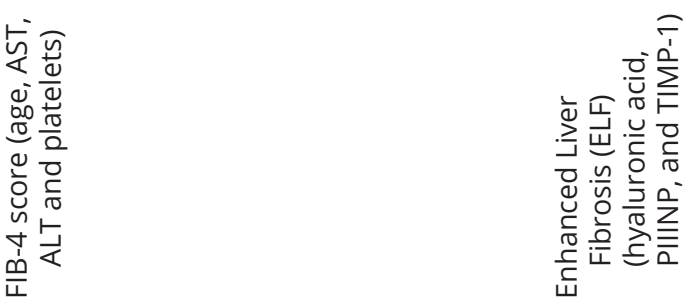

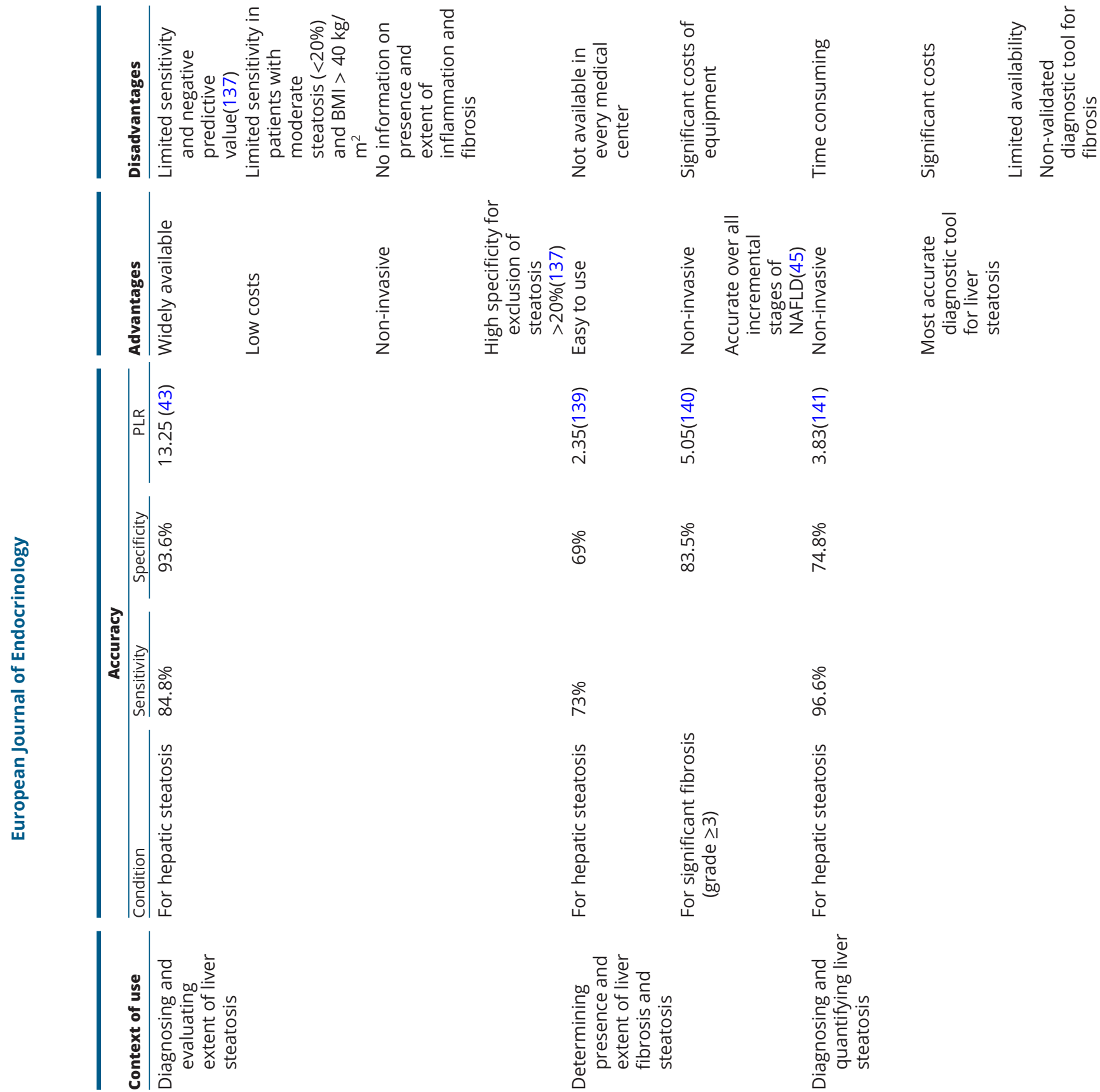

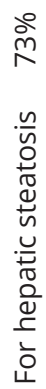
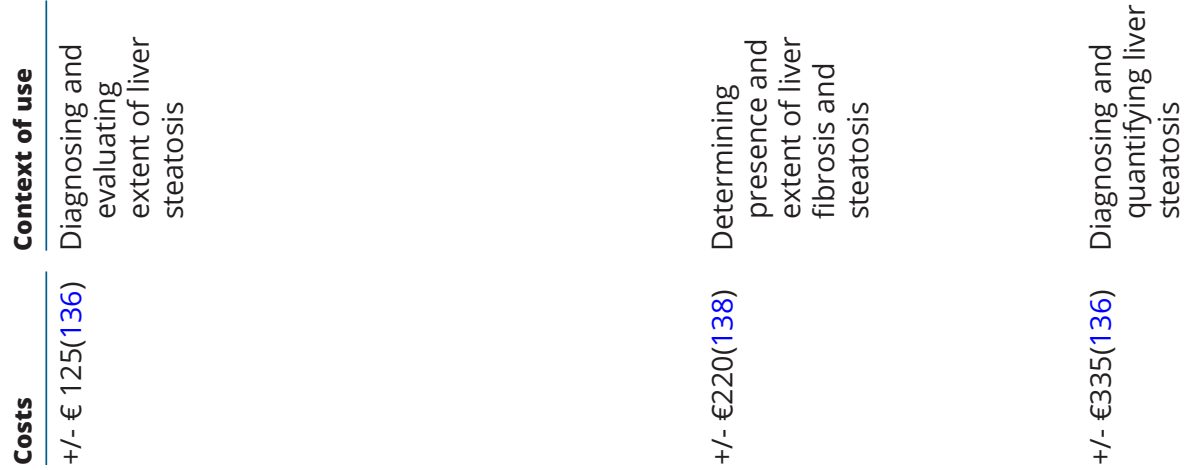

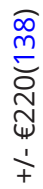

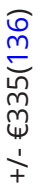
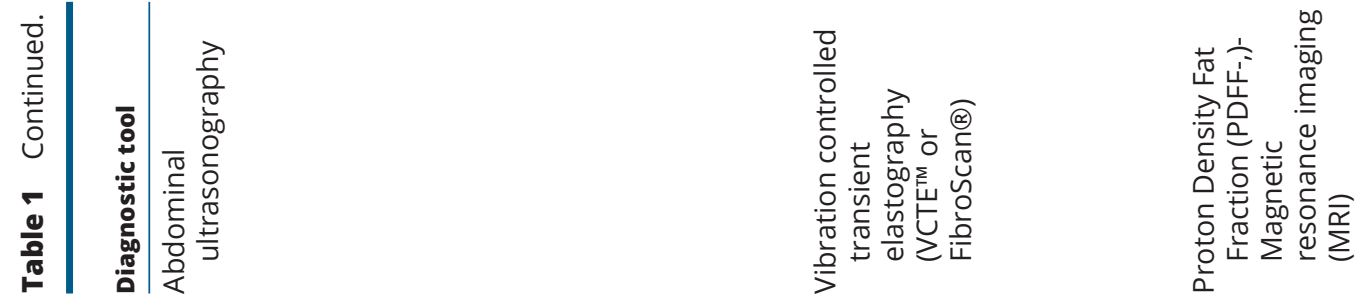

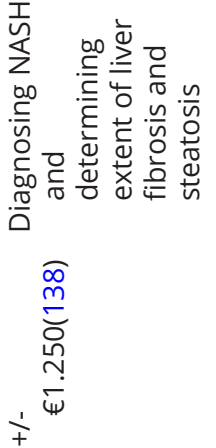

ฝิ
To date, liver biopsy remains the gold standard for diagnosing NASH, in which the characteristic swelling of hepatocytes (ballooning) and lobular inflammation can be established (Fig. 1). An important additional benefit of liver biopsy is the possibility to assess the presence and extent of liver fibrosis. However, liver biopsy is an invasive procedure that can be painful, has a risk of postbiopsy bleeding (up to $2 \%$ ) and might convey a sampling error, due to only about $1 / 50.000^{\text {th }}$ of the liver tissue being analysed, while NAFLD is often not equally distributed throughout the liver (48).

Clear numbers on specificity, sensitivity and potential risks of the diagnostic tools listed above are lacking because of large differences in methodology of clinical studies, which hampers their comparability. Therefore, diagnostic decisions should be made individually based on the specific case, the available diagnostic tools and the potential harms and benefits of the different diagnostic tools. Table 1 shows an overview of the advantages and disadvantages of available diagnostic tools (49).

\section{Clinical consequences}

Patients with NAFLD are at increased risk of atherosclerotic cardiovascular disease (asCVD). A recent meta-analysis showed that NAFLD was associated with an increased risk of fatal and non-fatal cardiovascular disease (odds ratio 2.58 (1.78-3.75)) (50). Interestingly, in patients with recently diagnosed myocardial infarction, the severity of stenosis on coronary angiography was found to correlate with the degree of hepatic steatosis on conventional ultrasound as well as VCTE-CAP (50). Moreover, the cumulative risk for mortality has shown to be increased in patients with coronary disease and stage 3-steatosis compared to patients with coronary disease and stage 1and 2-steatosis $(51,52)$.

Whilst these studies all show a strong association between hepatic steatosis and cardiovascular disease, a recent European population-based cohort study with 120.795 NAFLD patients versus matched controls showed that when adjusting for age, smoking, diabetes, hypertension, total cholesterol levels and statin use the hazard ratios for acute myocardial infarction (AMI) are lower than firstly calculated (53). This suggests that NAFLD is likely not an independent risk factor for asCVD, but may be driving asCVD by exacerbating risk factors like hypertension, insulin resistance and dyslipidaemia (50, 54). Causal pathways by which NAFLD may drive asCVD are the mixed dyslipidaemia, as well as proinflammatory 
and prothrombotic factors, most notably PAI-1. Favouring the lipid link and as mentioned previously, Mendelian randomization studies show that variation in the gene PNPLA3, involved in steatosis without affecting plasma lipid levels, does not increase the risk of asCVD, whereas variation in TM6SF2, affecting both steatosis and plasma VLDL, does increase asCVD risk (55). In addition to asCVD, NAFLD is related to cardiovascular disease by influencing left ventricular function. A recent study showed decreased left ventricular function within patients with NAFLDfibrosis (56).

Given the strong association between NAFLD, mixed lipidaemia and asCVD, treatment with statins to lower the lipid levels and decrease the risk on the development of cardiovascular events is important and has shown to be safe in a variety of large studies (57).

Besides this increased risk of adverse cardiovascular outcomes, increasing evidence has shown NAFLD can develop into a seriously harmful disease also with regards to liver-related outcomes, contrary to previous beliefs (58). Especially in patients with active disease, i.e. NASH, the formation of fibrosis and cirrhosis increases morbidity and mortality. A recent meta-analysis has shown that for patients with NASH it takes circa 7.1 years to progress 1 stage in fibrosis compared to circa 14.3 years for patients with simple steatosis (59). Importantly, NAFLD patients with T2DM are at higher risk of developing advanced liver fibrosis than NAFLD patients without diabetes $(60,61)$. Data from the American Transplant Registry show that in 2018, NAFLD/NASH-related cirrhosis became the main indication for liver transplantation, overtaking other liver diseases such as viral hepatitis and alcoholic liver disease (ALD), and this indication is on the rise in Europe as well $(62,63)$. An additional problem is that the amount of liver donors with signs of NAFLD is also rising, increasing the risk of post-transplantation complications for the recipient (63).

Since liver cirrhosis is a well-known risk factor for development of HCC, patients with cirrhosis need to be regularly screened. However, not seldom HCC is diagnosed in patients that were unfamiliar to have NAFLD, even without cirrhosis (64). Possibly due to lack of screening, patients with NAFLD that develop HCC have decreased survival rates compared to HCC patients with underlying alcoholic liver cirrhosis (65). Screening for HCC in NAFLD patients is however debatable, since the incidence of HCC in NAFLD patients is low, demonstrated by a large metaanalysis that found an annual incidence of 0.44 per 1000 person-years. In patients diagnosed with NASH, the HCC incidence was 5.29 per 1000 person-years (5).

\section{Treatment}

The complexity of the various pathways involved in the development of NAFLD complicates the treatment of this disease. Given the strong association with obesity and T2DM, lifestyle changes and weight loss are major targets in treatment of NAFLD and NASH. However, the increasing knowledge on an abundance of pathophysiological mechanisms that are involved, combined with the increase in incidence and severity of this disease has led to an enormous pharmaceutical development $(66,67)$.

\section{Lifestyle and nutritional interventions}

Lifestyle intervention is the most important factor in the treatment of NAFLD $(68,69)$. A weight reduction of $8 \%$ has been shown to result in a $50 \%$ decrease in liver fat (69). Yet an increase in physical activity without any reduction in body weight also has a positive effect on hepatic steatosis (69). In patients with NASH, a strict 52 -week programme of physical activity and diet resulted in a resolution of NASH in $25 \%$ of patients and $19 \%$ of patients showed regression of fibrosis. The extent of weight loss was associated with the level of improvement in histologic features of NASH. However, the vast majority of patients in this study did not reach the 5\% weight loss goal, reflecting the difficulty of lifestyle changes in this specific population (70). On the other hand, studies have shown that doubling of daily calorie intake in healthy volunteers with so-called fast food resulted in elevated plasma ALT levels and increased steatosis within 4 weeks (71).

Especially foods and beverages containing large amounts of fructose, like sodas, have shown to have a cumulative effect on the development of NAFLD and even fibrosis (72). Lifestyle changes and weight reduction are expected to remain centrally important within the treatment of NAFLD, since they not only exert positive effects on NAFLD but also on associated metabolic and cardiovascular diseases. Even modest alcohol use has been shown to mitigate the ability of the body to resolve NASH and is associated with increased serum liver enzymes, suggesting patients with NAFLD should completely cease their alcohol use (73). Moreover, certain dietary changes, like the Mediterranean diet, consisting of mainly single unsaturated fats derived from fish or olive oil, help to reduce the amount of liver fat and insulin insensitivity, even without inducing body weight reduction (74). Limiting the amount of free sugars in the diet was also shown to have a positive effect on NAFLD (69). 
Interestingly, the use of three or more cups of coffee a day protects against NAFLD and the formation of fibrosis, possibly through an increase in autophagia of lipid droplets within hepatocytes (75).

However, not only caloric intake, but also dietary composition has shown to play a role through dysbiosis of the gut microbiota, which most likely contributes to the development of NAFLD and NASH $(27,76,77,78,79)$. A diet rich in lipids, animal-derived proteins and sugars provides a more favourable culture medium for certain bacterial species (like Bacteroides) than for others $(80,81)$. However, the mechanisms that underlie the development of NASH through microbiome imbalance are not fully understood. One hypothesis is that certain bacterial compositions increase gut permeability, thereby exposing the portal vein and liver to (products of) gut bacteria that induce various inflammatory pathways. Another hypothesis is that gut bacteria may induce or protect against NAFLD by producing pro- or anti-inflammatory metabolites. Both harmful metabolites, such as alcohol, as well as protective metabolites, like butyrate produced by Eubacterium hallii, have been identified as possible mechanisms in the development of hepatic steatosis in recent murine models (82). A recent study revealed that presence of high-alcohol-producing strains of Klebsiella pneumoniae in the gut was strongly associated with disease severity in a Chinese cohort of NAFLD patients, and that this strain could reproduce fatty liver disease in murine models. The endogenous alcohol production of these bacteria might activate similar molecular mechanisms as in fatty liver disease mediated by habitual excessive alcohol consumption, which is microscopically nearly indistinguishable from NAFLD (83).

Animal models suggest that influencing the gut microbial composition by using probiotics can reduce NAFLD (80). In humans, a recent placebo-controlled pilot study in 20 patients with biopsy-proven NAFLD revealed a decrease in hepatic steatosis after 6 months of treatment with probiotics consisting of various species such as L. plantarum, L. delbueckii spp. bulgaricus, L. acidophilus, Lactobacillus rhamnosus and Bifidobacterium bifidum. A decrease in hepatic steatosis was found, which was associated with an increase in Bacteroides and a decrease of Firmicutes species (84).

Gut bacteria also play an important role in the modification of bile acids. The dysbiosis of the microbiome can lead to alterations in bile acid composition, potentially modifying the absorption and metabolism of lipids, resulting in a dysregulation of energy metabolism $(28,85)$.

\section{Bariatric surgery and endobariatric procedures}

Bariatric surgery has been proven to be very effective in NALFD patients, a reduction in body weight of over $10 \%$ can lead to complete regression of hepatic inflammation and fibrosis $(86,87)$. The Lille Bariatric cohort study showed that in morbidly obese patients with biopsyproven NASH, bariatric surgery (i.e. gastric banding, sleeve gastrectomy and gastric bypass) resulted in a resolution of NASH in $85 \%$ of patients and a reduction in fibrosis (86). Gastric bypass has been shown to be more effective in improving NAFLD and NASH compared to other procedures (88).

Moreover, new endobariatric techniques have been developed to fill the gap for patients who do not qualify for bariatric surgery or prefer less invasive strategies. Endoscopic gastroplication has shown to be a durable, less invasive therapy providing results similar to sleeve gastrectomy. But also other endobariatric procedures like space-occupying devices, aspiration therapy and endoscopic small bowel bypass therapies have been proven to be successful in inducing weight loss $(89,90)$. A single-centre retrospective cohort study following 135 patients with obesity and NAFLD undergoing intragastric balloon (IGB) treatment revealed changes in BMI after 6 months, as well as corresponding improvement of ALT, GGT and insulin resistance (HOMA-IR) scores (91). However, as endobariatric interventions are often temporary or less durable than bariatric surgery, aggressive weight maintenance afterwards is key for lasting weight reduction.

\section{Pharmacological developments}

Blood glucose-lowering drugs

Due to the close link between NAFLD and glycaemic dysregulation, blood glucose-lowering drugs also retain therapeutic effects in patients with hepatic steatosis. Treatment with metformin, a mainstay therapy in T2DM, showed to be associated to mitigation of steatosis in patients with NASH (92) and to prevent hepatic events in T2DM patients with advanced NASH (93).

Whereas metformin mainly affects hepatic insulin resistance, GLP-1-receptor agonists and analogues (liraglutide and semaglutide, respectively exenatide) have direct effects on pancreatic insulin production and also impact the heart, brain and gastrointestinal system (94). Despite the lack of unambiguous data about a direct effect of these medications on the liver, studies have suggested liraglutide to have a positive effect on NASH and the 
formation of fibrosis by reducing body weight, even in patients without T2DM (95). Moreover, liraglutide has shown to result in a reduction of asCVD events in patients with T2DM (96). However, strict rules for financial reimbursement for these medications, limiting off-label clinical use, and the need for s.c. injections to administer the drugs are hampering broader clinical implications. An oral form of the GLP-1 analogue semaglutide is currently in development for the treatment of NAFLD (66) and has already shown to have positive results in patients with T2DM in a phase 3-study (97).

Another group of therapeutics, SGLT2 inhibitors, such as canagliflozin, dapagliflozin and empaglifozin, selectively block the sodium glucose cotransporter 2 in the kidneys, thereby inhibiting renal glucose reabsorption in the proximal tubule. This increases urinary glucose excretion and reduces blood glucose levels in patients with T2DM. Results from multiple clinical NAFLD trials have shown SGLT2 inhibitors to significantly decrease serum liver enzyme levels compared to other oral glucoselowering agents (98). Moreover, animal models of NASH demonstrated that treatment with SGLT2 inhibitors could prevent the development of hepatic steatosis and fibrosis, possibly by promoting fat utilization and by reducing de novo lipogenesis in the liver (99). In addition, canagliflozin has demonstrated to reduce asCVD events in patients with T2DM (100). However, SGLT2 inhibitors increase the risk of diabetic ketoacidosis, urinary tract infections and hypotension and dehydration, and the effect is minimized by the amount of serum glucose that can be excreted via the urine, which is estimated at $50 \%$. The alleviation of hyperglycaemia and the induction of weight loss only partially explain the extent of NAFLD improvement with SGLT2 inhibitors, suggesting the involvement of other, still unknown pathways. Because of safety concerns and the limited effects of the established drugs on-going research is seeking novel/safer SGLT2 inhibitors.

Furthermore, thiazolidinediones like pioglitazone and rosiglitazone (withdrawn from the market in 2010), which increase insulin sensitivity, have been shown to exert positive effects on NAFLD through PPAR $\gamma$-agonism (101, $102,103)$. Unfortunately, they have disadvantages such as an increase in body weight, negative cardiovascular effects (mainly rosiglitazone) and a possible increased risk of bladder cancer (104).

\section{Inflammation and necro-apoptosis}

Selonsertib is an ASK1 inhibitor that was recently investigated in two phase 3-studies, one in F3-fibrosis and one in F4-fibrosis. Both studies report negative, that is, no significant effect of selonsertib on hepatic steatosis, inflammation or fibrosis $(105,106)$.

\section{CCR2/5 antagonists}

Cenicriviroc is a CCR2/5 antagonist, inhibiting macrophages in the peripheral fat tissue, which improves insulin sensitivity and inhibits migration, activation and proliferation of stellate cells. A phase 2 trial concluded cenicriviroc has positive effects on hepatic steatosis, inflammation and fibrosis and a phase 3-trial is currently being performed $(107,108)$.

\section{Vitamin $E$}

Vitamin $\mathrm{E}$ is a well-known antioxidant and exerts a positive effect on the amount of liver fat when prescribed in high doses (800 IE a day) (103). Unfortunately, no data have been collected on the effect of vitamin $\mathrm{E}$ on fibrosis, and high doses also seem to increase risk of prostate cancer and cerebrovascular accidents (CVA) $(109,110)$. The European Association for the Study of the Liver (EASL) Clinical Practice Guidelines (developed in collaboration with the associations for diabetes and obesity) advise to consider vitamin $\mathrm{E}$ for patients with severe NAFLD (without T2DM) (3).

\section{Lipid-lowering drugs}

Although there have been safety concerns in the past about the prescription of statins in patients with elevated serum liver enzymes, these medications seem to have positive effects not only by decreasing risk of cardiovascular disease but also by inhibiting formation of hepatic fibrosis (111). Moreover, multiple agents are being developed to block the de novo lipogenesis within the liver, most notably ACC-inhibitors, and phase 2 and 3-trials are expected to read out in the near future (58).

\section{Thyromimetics}

Thyroid hormone and thyroid mimetics have the potential to reduce NAFLD-NASH. There are signs that these hormones exert positive effects on hepatic steatosis by mediating the induction of autophagia of lipid droplets and mitochondrial beta-oxidation of fatty acids (112). In 20 patients with T2DM and NAFLD, a low dose of thyroid hormone resulted in significant reduction of intrahepatic fat, measured by MRI-PDFF (113). A phase 2-trial in which 
78 NASH patients were treated with a selective thyroid hormone receptor beta-agonist showed a significant reduction of intrahepatic fat measured by MRI-PDFF and an improvement of NASH on liver biopsy after 36 weeks (114). Therefore, a phase-3 trial with this selective thyroid hormone receptor beta-agonist is ongoing (115).

\section{Bile acids}

Besides their function in the absorption of lipids in the gut, there is accumulating evidence suggesting that bile acids also play a major role as signalling molecules in the liver and gut. Bile acids regulate the energy metabolism of lipids, sugars and proteins $(28,116)$. There are multiple on-going clinical trials using bile acid derivatives and mimetics as possible treatment for NASH $(117,118,119$, $120,121,122)$

Ursodeoxycholic acid (a tertiary bile acid) and colesevelam (an anion exchange resin) have no effect on the amount of liver fat $(65,123)$. However, in the phase2 FLINT trial the FXR-agonist obeticholic acid (OCA) did result in a histologic response of NASH in $46 \%$ of the participants with $25 \mathrm{mg}$ a day (compared to 21\% in the placebo group) (124). Unfortunately, a commonly reported side effect (23\%) was pruritus, as well as an elevation in plasma LDL, due to increased lipoprotein lipase (LPL) activity. Interim analysis of the REGENERATE trial, a phase-3 trial concerning OCA in NASH, showed a small but significant reduction of fibrosis compared to the placebo group (125).

\section{Combination therapy}

Because of the complex pathogenesis of the disease, future medical treatment of progressive NAFLD is expected to consist of combination therapy, analogous to the current treatment of T2DM and hypertension. This expectation is so strong, that two types of combination therapy are already being investigated in clinical trials, even before the first monotherapy for NAFLD has been registered. In the phase-2 TANDEM trial, the FXR-agonist tropifexor is combined with cenicriviroc (126). In the phase-2 ATLAS trial, selonsertib is being combined with ACC-inhibition and a FXR-agonist. An early interim analysis did not show synergy in reducing hepatic steatosis on MRI-PDFF, yet the final results have to be awaited (127). Interestingly, both studies combine a drug that acts upstream (insulin sensitivity/lipotoxicity) in the pathogenesis of NAFLD with a drug that acts more downstream (apoptosis, fibrosis), which seems a highly plausible approach. Another recent randomized controlled trial investigated the combination of OCA and atorvastatin in NASH patients. It was shown that the OCA-dependent rise in LDL can be mitigated by atorvastatin, offering a potentially safer treatment option for NASH than OCA alone (128).

\section{Multidisciplinary approach}

NAFLD has become a serious health problem and patients with NAFLD often suffer from major cardiometabolic comorbidities. In recognizing patients with a high-risk profile for the development of $\mathrm{NASH}$, the collaboration of the general practitioner, assistant nurse, internistendocrinologist, vascular specialist and hepatologist is essential. In many medical centres across the globe, initiatives to develop a NASH-workgroup have sprouted, to stimulate this collaboration.

When patients are diagnosed with NAFLD, it is often not well recognized which patients suffer from nonprogressive simple steatosis, which patients suffer from the metabolically active NASH with high risk of developing cardiovascular diseases and which patients have a high risk of developing cirrhosis and HCC. Developing more accurate and non-invasive diagnostic tools is necessary for a better capability of screening and differentiating between the different stages of liver disease, providing estimations for the chance of progression and the development of cirrhotic complications including HCC.

Meanwhile, in the absence of a widely available, accurate, non-invasive diagnostic tool, Fig. 3 provides recommendations for screening, diagnostics and surveillance in (suspected) NAFLD cases. It is advised to screen patients with a high risk for NAFLD by three-yearly measurements of serum liver enzymes or ultrasonography. In case of elevated serum liver enzymes or steatosis on ultrasound, screening for the presence of severe fibrosis or cirrhosis by $\mathrm{VCTE}^{\mathrm{TM}}$ or FibroScan ${ }^{\circledR}$ is indicated. In the presence of severe fibrosis or cirrhosis, surveillance of HCC should take place every 6 months. In case of portal hypertension screening for oesophageal varices is also indicated.

Another area of concern for these patients is the high risk of the development of cardiovascular diseases. Intensifying support for lifestyle improvement and treating comorbidities remains the cornerstone in halting the progression of liver disease and preventing cardiovascular complications of NAFLD. No clear pharmaceutical treatment has yet been established for NAFLD. However, considering the numerous on-going 


\section{Primary and secondary care}

Secondary care

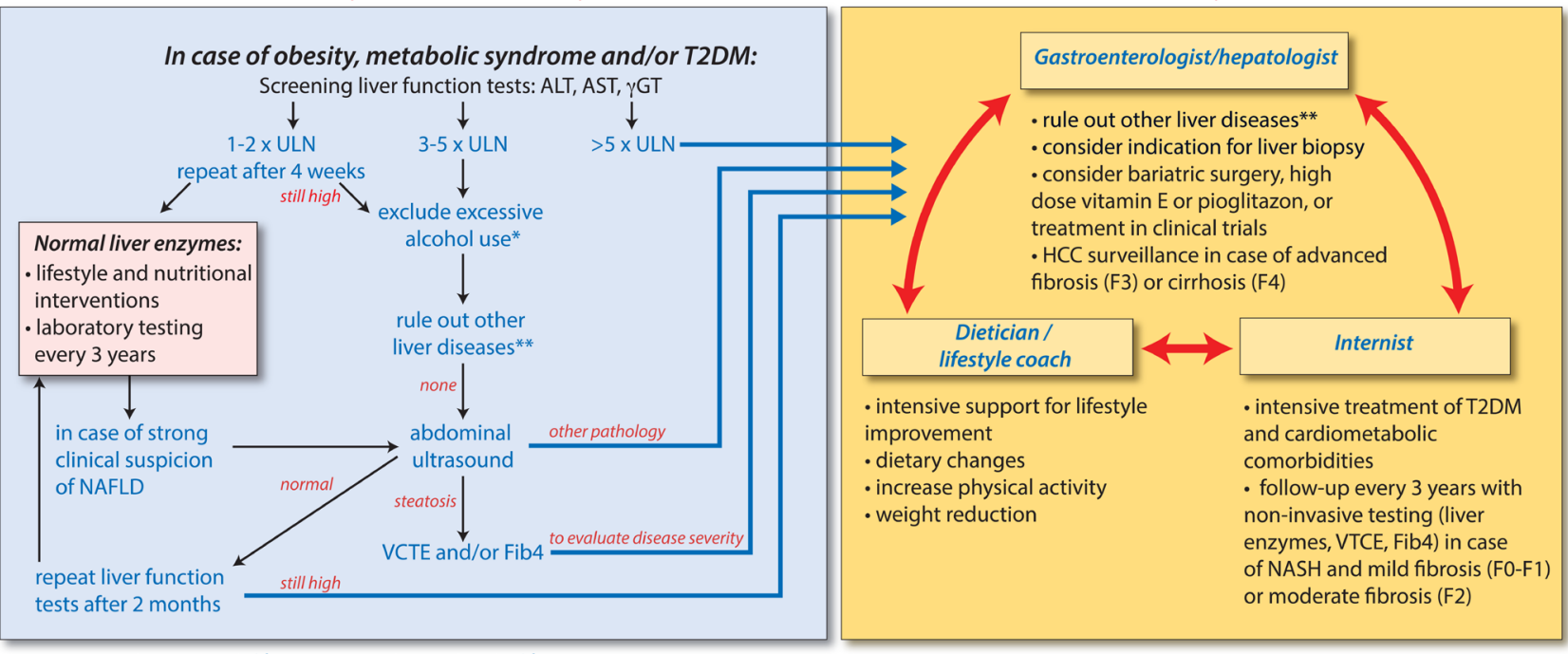

* women: maximum 1 unit/day; men: maximum 2 units/day

** viral hepatitis, drug-induced liver diseases, auto-immune liver diseases, hemochromatosis, Wilson's disease, alpha-1 antitrypsin deficiency

\section{Figure 3}

Multidisciplinary approach to non-alcoholic fatty liver disease (NAFLD).

trials, the development of therapeutic agents is expected in the near future. Until then, individual considerations have to be made in which therapeutic abilities, patient characteristics, patient preferences and potential harms and benefits of different treatment strategies should be taken into account. A multidisciplinary approach is essential to identify the patient population in need of this care and to ensure it being delivered. With this intent the flow chart in Fig. 3 has been composed, based on screening methods used in the United Kingdom and current guidelines $(3,35,39,45,129,130)$.

\section{Conclusion}

The increasing prevalence of NAFLD/NASH is worrisome, rendering this spectrum of liver disease a major global health problem. The challenge to distinguish mild stages from progressive stages of NAFLD and the upcoming advent of specific pharmacotherapy both require improvement of care paths for patients with NAFLD, guided by multidisciplinary guidelines and modules. Together this renders the clinical developments and scientific efforts within the field of NAFLD both very challenging and highly fascinating.

\section{Declaration of interest}

A G H has received a research grant from Novo Nordisk and a Gilead Research Scholarschip Grant. A G H and M E T have received consulting fees from Gilead. The other authors have nothing to disclose.

\section{Funding}

A G H is supported by the Amsterdam UMC Fellowship grant, a Holland Health TKI-PPP grant and by the Gilead Research scholarship grant.

\section{Author contribution statement}

M M R, A L M, U B, M E T and A G H wrote the manuscript together and interpreted the results. $U B, M E T$ and $A G H$ did the final review of the manuscript. M E T and A G H are the guarantors of this work and, as such, had access to all articles and take responsibility for the integrity of the article and the data mentioned. All authors approved the final version of the manuscript. M E Tushuizen and A G Holleboom are Joint senior author.

\section{Acknowledgement}

The authors thank our medical illustrator Ron Slagter.

\section{References}

1 Friedman SL, Neuschwander-Tetri BA, Rinella M \& Sanyal AJ. Mechanisms of NAFLD development and therapeutic strategies. Nature Medicine 201824 908-922. (https://doi.org/10.1038/s41591018-0104-9)

2 Arab JP, Arrese M \& Trauner M. Recent insights into the pathogenesis of nonalcoholic fatty liver disease. Annual Review of Pathology 201813 321-350. (https://doi.org/10.1146/annurevpathol-020117-043617)

3 EASL-EASD-EASO. Clinical practice guidelines for the management of non-alcoholic fatty liver disease. Journal of Hepatology $2016 \mathbf{6 4}$ 1388-1402. (https://doi.org/10.1016/j.jhep.2015.11.004)

4 Younossi Z, Anstee QM, Marietti M, Hardy T, Henry L, Eslam M, George J \& Bugianesi E. Global burden of NAFLD and NASH: trends, predictions, risk factors and prevention. Nature Reviews Gastroenterology and Hepatology 201715 11. (https://doi.org/10.1038/ nrgastro.2017.109) 
5 Younossi ZM, Golabi P, de Avila L, Paik JM, Srishord M, Fukui N, Qiu Y, Burns L, Afendy A \& Nader F. The global epidemiology of NAFLD and NASH in patients with type 2 diabetes: a systematic review and meta-analysis. Journal of Hepatology 201971 793-801. (https://doi.org/10.1016/j.jhep.2019.06.021)

6 Vernon G, Baranova A \& Younossi ZM. Systematic review: the epidemiology and natural history of non-alcoholic fatty liver disease and non-alcoholic steatohepatitis in adults. Alimentary Pharmacology and Therapeutics 201134 274-285. (https://doi.org/10.1111/j.13652036.2011.04724.x)

7 Koehler EM, Schouten JN, Hansen BE, van Rooij FJ, Hofman A, Stricker BH \& Janssen HL. Prevalence and risk factors of nonalcoholic fatty liver disease in the elderly: results from the Rotterdam study. Journal of Hepatology 201257 1305-1311. (https://doi. org/10.1016/j.jhep.2012.07.028)

8 van den Berg EH, Amini M, Schreuder TC, Dullaart RP, Faber KN, Alizadeh BZ \& Blokzijl H. Prevalence and determinants of nonalcoholic fatty liver disease in lifelines: a large Dutch population cohort. PLoS ONE 201712 e0171502. (https://doi.org/10.1371/ journal.pone.0171502)

9 Lazarus JV, Ekstedt M, Marchesini G, Mullen J, Novak K, Pericas JM, Roel E, Romero-Gomez M, Ratziu V, Tacke F et al. A cross-sectional study of the public health response to non-alcoholic fatty liver disease in Europe. Journal of Hepatology 202072 14-24. (https://doi. org/10.1016/j.jhep.2019.08.027)

10 Diehl AM \& Day C. Cause, pathogenesis, and treatment of nonalcoholic steatohepatitis. New England Journal of Medicine 377 2063-2072. (https://doi.org/10.1056/NEJMra1503519)

11 Donnelly KL, Smith CI, Schwarzenberg SJ, Jessurun J, Boldt MD \& Parks EJ. Sources of fatty acids stored in liver and secreted via lipoproteins in patients with nonalcoholic fatty liver disease. Journal of Clinical Investigation 2005115 1343-1351. (https://doi. org/10.1172/JCI23621)

12 Hardy T, Oakley F, Anstee QM \& Day CP. Nonalcoholic fatty liver disease: pathogenesis and disease spectrum. Annual Review of Pathology 201611 451-496. (https://doi.org/10.1146/annurevpathol-012615-044224)

13 Isokuortti E, Zhou Y, Peltonen M, Bugianesi E, Clement K, BonnefontRousselot D, Lacorte JM, Gastaldelli A, Schuppan D, Schattenberg JM et al. Use of HOMA-IR to diagnose non-alcoholic fatty liver disease: a population-based and inter-laboratory study. Diabetologia 201760 1873-1882. (https://doi.org/10.1007/s00125-017-4340-1)

14 Maeda Junior AS, Constantin J, Utsunomiya KS, Gilglioni EH, Gasparin FRS, Carreno FO, de Moraes SMF, Rocha M, Natali MRM, Ghizoni CVC et al. Cafeteria diet feeding in young rats leads to hepatic steatosis and increased gluconeogenesis under fatty acids and glucagon influence. Nutrients 2018101571 . (https://doi.org/10.3390/ nu10111571)

15 DeFronzo RA. Insulin resistance, lipotoxicity, type 2 diabetes and atherosclerosis: the missing links. The Claude Bernard Lecture 2009. Diabetologia 201053 1270-1287. (https://doi.org/10.1007/s00125010-1684-1)

16 Musso G, Cassader M, Paschetta E, Gambino R. Bioactive lipid species and metabolic pathways in progression and resolution of nonalcoholic steatohepatitis. Gastroenterology 2018155 282.e8-302. e8. (https://doi.org/10.1053/j.gastro.2018.06.031)

17 Hafizi Abu Bakar M, Kian Kai C, Wan Hassan WN, Sarmidi MR, Yaakob H \& Zaman Huri H. Mitochondrial dysfunction as a central event for mechanisms underlying insulin resistance: the roles of long chain fatty acids. Diabetes/Metabolism Research and Reviews 201531 453-475. (https://doi.org/10.1002/dmrr.2601)

18 Musso G, Cassader M \& Gambino R. Non-alcoholic steatohepatitis: emerging molecular targets and therapeutic strategies. Nature Reviews Drug Discovery 201615 249-274. (https://doi.org/10.1038/ nrd.2015.3)
19 Sano R \& Reed JC. ER stress-induced cell death mechanisms. Biochimica et Biophysica Acta 20131833 3460-3470. (https://doi. org/10.1016/j.bbamcr.2013.06.028)

20 Rotundo L, Persaud A, Feurdean M, Ahlawat S \& Kim HS. The Association of leptin with severity of non-alcoholic fatty liver disease: a population-based study. Clinical and Molecular Hepatology 201824 392-401. (https://doi.org/10.3350/cmh.2018.0011)

21 Saxena NK, Titus MA, Ding X, Floyd J, Srinivasan S, Sitaraman SV $\&$ Anania FA. Leptin as a novel profibrogenic cytokine in hepatic stellate cells: mitogenesis and inhibition of apoptosis mediated by extracellular regulated kinase (Erk) and Akt phosphorylation. FASEB Journal: Official Publication of the Federation of American Societies for Experimental Biology 200418 1612-1614. (https://doi.org/10.1096/ fj.04-1847fje)

22 Udomsinprasert W, Honsawek S \& Poovorawan Y. Adiponectin as a novel biomarker for liver fibrosis. World Journal of Hepatology $2018 \mathbf{1 0}$ 708-718. (https://doi.org/10.4254/wjh.v10.i10.708)

23 Zhou Y, Ren H, Dai B, Li J, Shang L, Huang J \& Shi X. Hepatocellular carcinoma-derived exosomal miRNA-21 contributes to tumor progression by converting hepatocyte stellate cells to cancer-associated fibroblasts. Journal of Experimental and Clinical Cancer Research: $C R$ 2018;37 324. (https://doi.org/10.1186/s13046-018-0965-2)

24 Wang X, Zheng Z, Caviglia JM, Corey KE, Herfel TM, Cai B, Masia R, Chung RT, Lefkowitch JH, Schwabe RF et al. Hepatocyte TAZ/WWTR1 promotes inflammation and fibrosis in nonalcoholic steatohepatitis. Cell Metabolism 201624 848-862. (https://doi.org/10.1016/j. cmet.2016.09.016)

25 Lebensztejn DM, Flisiak-Jackiewicz M, Bialokoz-Kalinowska I, BobrusChociej A \& Kowalska I. Hepatokines and non-alcoholic fatty liver disease. Acta Biochimica Polonica 201663 459-467. (https://doi. org/10.18388/abp.2016_1252)

26 De Chiara F, Heeboll S, Marrone G, Montoliu C, Hamilton-Dutoit S, Ferrandez A, Andreola F, Rombouts K, Gronbaek H, Felipo V et al. Urea cycle dysregulation in non-alcoholic fatty liver disease. Journal of Hepatology 201869 905-915. (https://doi.org/10.1016/j. jhep.2018.06.023)

27 Leung C, Rivera L, Furness JB \& Angus PW. The role of the gut microbiota in NAFLD. Nature Reviews Gastroenterology and Hepatology 201613 412-425. (https://doi.org/10.1038/nrgastro.2016.85)

28 Trauner M, Claudel T, Fickert P, Moustafa T \& Wagner M. Bile acids as regulators of hepatic lipid and glucose metabolism. Digestive Diseases 201028 220-224. (https://doi.org/10.1159/000282091)

29 Anstee QM \& Day CP. The genetics of NAFLD. Nature Reviews Gastroenterology and Hepatology 201310 645-655. (https://doi. org/10.1038/nrgastro.2013.182)

30 Li TT, Li TH, Peng J, He B, Liu LS, Wei DH, Jiang ZS, Zheng XL $\&$ Tang ZH. TM6SF2: a novel target for plasma lipid regulation. Atherosclerosis 2018268 170-176. (https://doi.org/10.1016/j. atherosclerosis.2017.11.033)

31 Buch S, Stickel F, Trepo E, Way M, Herrmann A, Nischalke HD, Brosch M, Rosendahl J, Berg T, Ridinger $\mathrm{M}$ et al. A genome-wide association study confirms PNPLA3 and identifies TM6SF2 and MBOAT7 as risk loci for alcohol-related cirrhosis. Nature Genetics 201547 1443-1448. (https://doi.org/10.1038/ng.3417)

32 Abul-Husn NS, Cheng X, Li AH, Xin Y, Schurmann C, Stevis P, Liu Y, Kozlitina J, Stender S, Wood GC et al. A protein-truncating HSD17B13 variant and protection from chronic liver disease. New England Journal of Medicine 2018378 1096-1106. (https://doi. org/10.1056/NEJMoa1712191)

33 Wong VWS, Wong GLH, Tsang SWC, Hui AY, Chan AWH, Choi PCL, Chim AML, Chu S, Chan FKL, Sung JJY et al. Metabolic and histological features of non-alcoholic fatty liver disease patients with different serum alanine aminotransferase levels. Alimentary Pharmacology \& Therapeutics 200929 387-396. (https://doi. org/10.1111/j.1365-2036.2008.03896.x) 
34 Bedogni G, Bellentani S, Miglioli L, Masutti F, Passalacqua M, Castiglione A \& Tiribelli C. The fatty liver index: a simple and accurate predictor of hepatic steatosis in the general population. BMC Gastroenterology 20066 33. (https://doi.org/10.1186/1471230X-6-33)

35 Shah AG, Lydecker A, Murray K, Tetri BN, Contos MJ \& Sanyal AJ. Comparison of noninvasive markers of fibrosis in patients with nonalcoholic fatty liver disease. Clinical Gastroenterology and Hepatology 20097 1104-1112. (https://doi.org/10.1016/j. cgh.2009.05.033)

36 Cuthbertson DJ, Weickert MO, Lythgoe D, Sprung VS, Dobson R, Shoajee-Moradie F, Umpleby M, Pfeiffer AF, Thomas EL, Bell JD et al. External validation of the fatty liver index and lipid accumulation product indices, using $1 \mathrm{H}$-magnetic resonance spectroscopy, to identify hepatic steatosis in healthy controls and obese, insulinresistant individuals. European Journal of Endocrinology 2014171 561-569. (https://doi.org/10.1530/EJE-14-0112)

37 Vanni E \& Bugianesi E. Editorial: utility and pitfalls of Fatty Liver Index in epidemiologic studies for the diagnosis of NAFLD. Alimentary Pharmacology \& Therapeutics 201541 406-407. (https:// doi.org/10.1111/apt.13063)

38 Sun W, Cui H, Li N, Wei Y, Lai S, Yang Y, Yin X \& Chen DF. Comparison of FIB-4 index, NAFLD fibrosis score and BARD score for prediction of advanced fibrosis in adult patients with non-alcoholic fatty liver disease: a meta-analysis study. Hepatology Research 201646 862-870. (https://doi.org/10.1111/hepr.12647)

39 Vilar-Gomez E \& Chalasani N. Non-invasive assessment of nonalcoholic fatty liver disease: clinical prediction rules and blood-based biomarkers. Journal of Hepatology 201868 305-315. (https://doi. org/10.1016/j.jhep.2017.11.013)

40 Day JW \& Rosenberg WM. The enhanced liver fibrosis (ELF) test in diagnosis and management of liver fibrosis. British Journal of Hospital Medicine 201879 694-699. (https://doi.org/10.12968/ hmed.2018.79.12.694)

41 Initiative IM. Liver Investigation: Testing Marker Utility in Steatohepatitis, 2017. (available at: https://www.imi.europa.eu/ projects-results/project-factsheets/litmus)

42 Verhaegh P, Bavalia R, Winkens B, Masclee A, Jonkers D \& Koek G. Noninvasive tests do not accurately differentiate nonalcoholic steatohepatitis from simple steatosis: a systematic review and metaanalysis. Clinical Gastroenterology and Hepatology 201816 837-861. (https://doi.org/10.1016/j.cgh.2017.08.024)

43 Hernaez R, Lazo M, Bonekamp S, Kamel I, Brancati FL, Guallar E \& Clark JM. Diagnostic accuracy and reliability of ultrasonography for the detection of fatty liver: a meta-analysis. Hepatology 201154 1082-1090. (https://doi.org/10.1002/hep.24452)

44 Saadeh S, Younossi ZM, Remer EM, Gramlich T, Ong JP, Hurley M, Mullen KD, Cooper JN \& Sheridan MJ. The utility of radiological imaging in nonalcoholic fatty liver disease. Gastroenterology 2002123 745-750. (https://doi.org/10.1053/gast.2002.35354)

45 Eddowes PJ, Sasso M, Allison M, Tsochatzis E, Anstee QM, Sheridan D, Guha IN, Cobbold JF, Deeks JJ, Paradis V et al. Accuracy of fibroscan controlled attenuation parameter and liver stiffness measurement in assessing steatosis and fibrosis in patients with nonalcoholic fatty liver disease. Gastroenterology 2019156 1717-1730. (https://doi.org/10.1053/j.gastro.2019.01.042)

46 Caussy C, Reeder SB, Sirlin CB \& Loomba R. Noninvasive, quantitative assessment of liver fat by MRI-PDFF as an endpoint in NASH trials. Hepatology 201868 763-772. (https://doi.org/10.1002/ hep.29797)

47 Kim JW, Lee Y-S, Park YS, Kim B-H, Lee SY, Yeon JE \& Lee CH. Multiparametric MR index for the diagnosis of non-alcoholic steatohepatitis in patients with non-alcoholic fatty liver disease. Scientific Reports 202010 2671. (https://doi.org/10.1038/s41598-02059601-3)
48 Sanai FM \& Keeffe EB. Liver biopsy for histological assessment: the case against. Saudi Journal of Gastroenterology 201016 124-132. (https://doi.org/10.4103/1319-3767.61244)

49 Srivastava A, Jong S, Gola A, Gailer R, Morgan S, Sennett K, Tanwar S, Pizzo E, O'Beirne J, Tsochatzis E et al. Cost-comparison analysis of FIB-4, ELF and fibroscan in community pathways for non-alcoholic fatty liver disease. BMC Gastroenterology 201919 122. (https://doi. org/10.1186/s12876-019-1039-4)

50 Targher G, Byrne CD, Lonardo A, Zoppini G \& Barbui C. Nonalcoholic fatty liver disease and risk of incident cardiovascular disease: a meta-analysis. Journal of Hepatology 201665 589-600. (https://doi.org/10.1016/j.jhep.2016.05.013)

51 Friedrich-Rust M, Schoelzel F, Maier S, Seeger F, Rey J, Fichtlscherer S, Herrmann E, Zeuzem S \& Bojunga J. Severity of coronary artery disease is associated with non-alcoholic fatty liver dis-ease: a single-blinded prospective mono-center study. PLOS ONE 201712 e0186720. (https://doi.org/10.1371/journal.pone.0186720)

52 Keskin M, Hayiroglu MI, Uzun AO, Guvenc TS, Sahin S \& Kozan O. Effect of nonalcoholic fatty liver disease on in-hospital and longterm outcomes in patients with ST-segment elevation myocardial infarction. American Journal of Cardiology 2017120 1720-1726. (https://doi.org/10.1016/j.amjcard.2017.07.107)

53 Alexander M, Loomis AK, van der Lei J, Duarte-Salles T, PrietoAlhambra D, Ansell D, Pasqua A, Lapi F, Rijnbeek P, Mosseveld M et al. Non-alcoholic fatty liver disease and risk of incident acute myocardial infarction and stroke: findings from matched cohort study of 18 million European adults. BMJ 2019367 15367. (https:// doi.org/10.1136/bmj.15367)

54 Gastaldelli A, Kozakova M, Hojlund K, Flyvbjerg A, Favuzzi A, Mitrakou A \& Balkau B. Fatty liver is associated with insulin resistance, risk of coronary heart disease, and early atherosclerosis in a large European population. Hepatology 200949 1537-1544. (https://doi.org/10.1002/hep.22845)

55 Kahali B, Liu YL, Daly AK, Day CP, Anstee QM \& Speliotes EK. TM6SF2: catch-22 in the fight against nonalcoholic fatty liver disease and cardiovascular disease? Gastroenterology 2015148 679-684. (https://doi.org/10.1053/j.gastro.2015.01.038)

56 Canada JM, Abbate A, Collen R, Billingsley H, Buckley LF, Carbone S, Trankle CR, Idowu MO, Kadariya D, Van Tassell B et al. Relation of hepatic fibrosis in nonalcoholic fatty liver disease to left ventricular diastolic function and exercise tolerance. American Journal of Cardiology 2019123 466-473. (https://doi.org/10.1016/j.amjcard.2018.10.027)

57 Sigler MA, Congdon L \& Edwards KL. An evidence-based review of statin use in patients with nonalcoholic fatty liver disease. Clinical Medicine Insights: Gastroenterology 2018111179552218787502. (https://doi.org/10.1177/1179552218787502)

58 Estes C, Razavi H, Loomba R, Younossi Z \& Sanyal AJ. Modeling the epidemic of nonalcoholic fatty liver disease demonstrates an exponential increase in burden of disease. Hepatology 201867 123-133. (https://doi.org/10.1002/hep.29466)

59 Singh S, Allen AM, Wang Z, Prokop LJ, Murad MH \& Loomba R. Fibrosis progression in nonalcoholic fatty liver vs nonalcoholic steatohepatitis: a systematic review and meta-analysis of pairedbiopsy studies. Clinical Gastroenterology and Hepatology 201513643. e1-654.e9; quiz e39-e40. (https://doi.org/10.1016/j.cgh.2014.04.014)

60 Tada T, Toyoda H, Sone Y, Yasuda S, Miyake N, Kumada T \& Tanaka J. Type 2 diabetes mellitus: a risk factor for progression of liver fibrosis in middle-aged patients with non-alcoholic fatty liver disease. Journal of Gastroenterology and Hepatology 201934 2011-2018. (https://doi. org/10.1111/jgh.14734)

61 McPherson S, Hardy T, Henderson E, Burt AD, Day CP \& Anstee QM. Evidence of NAFLD progression from steatosis to fibrosingsteatohepatitis using paired biopsies: implications for prognosis and clinical management. Journal of Hepatology 201562 1148-1155. (https://doi.org/10.1016/j.jhep.2014.11.034) 
62 Flemming JA, Kim WR, Brosgart CL \& Terrault NA. Reduction in liver transplant wait-listing in the era of direct-acting antiviral therapy. Hepatology 201765 804-812. (https://doi.org/10.1002/hep.28923)

63 Haldar D, Kern B, Hodson J, Armstrong MJ, Adam R, Berlakovich G, Fritz J, Feurstein B, Popp W, Karam V et al. Outcomes of liver transplantation for non-alcoholic steatohepatitis: a European liver transplant registry study. Journal of Hepatology 201971 313-322. (https://doi.org/10.1016/j.jhep.2019.04.011)

64 Hester D, Golabi P, Paik J, Younossi I, Mishra A \& Younossi ZM. Among medicare patients with hepatocellular carcinoma, nonalcoholic fatty liver disease is the most common etiology and cause of mortality. Journal of Clinical Gastroenterology 201954 459-467. (https://doi.org/10.1097/MCG.0000000000001172)

65 Reddy SK, Steel JL, Chen HW, DeMateo DJ, Cardinal J, Behari J, Humar A, Marsh JW, Geller DA \& Tsung A. Outcomes of curative treatment for hepatocellular cancer in nonalcoholic steatohepatitis versus hepatitis C and alcoholic liver disease. Hepatology 201255 1809-1819. (https://doi.org/10.1002/hep.25536)

66 Drew L. Drug development: sprint finish. Nature 2017551 S86-S89. (https://doi.org/10.1038/d41586-017-06926-1)

67 Sumida Y \& Yoneda M. Current and future pharmacological therapies for NAFLD/NASH. Journal of Gastroenterology $2018 \mathbf{5 3}$ 362-376. (https://doi.org/10.1007/s00535-017-1415-1)

68 Houghton D, Thoma C, Hallsworth K, Cassidy S, Hardy T, Burt AD, Tiniakos D, Hollingsworth KG, Taylor R, Day CP et al. Exercise reduces liver lipids and visceral adiposity in patients with nonalcoholic steatohepatitis in a randomized controlled trial. Clinical Gastroenterology and Hepatology 201715 96-102.e3. (https:// doi.org/10.1016/j.cgh.2016.07.031)

69 Ratziu V. Non-pharmacological interventions in non-alcoholic fatty liver disease patients. Liver International 201737 (Supplement 1) 90-96. (https://doi.org/10.1111/liv.13311)

70 Vilar-Gomez E, Martinez-Perez Y, Calzadilla-Bertot L, TorresGonzalez A, Gra-Oramas B, Gonzalez-Fabian L, Friedman SL, Diago M \& Romero-Gomez M. Weight loss through lifestyle modification significantly reduces features of nonalcoholic steatohepatitis. Gastroenterology 2015149 367-378.e5; quiz e14-15. (https://doi.org/10.1053/j.gastro.2015.04.005)

71 Kechagias S, Ernersson A, Dahlqvist O, Lundberg P, Lindstrom T $\&$ Nystrom FH. Fast-food-based hyper-alimentation can induce rapid and profound elevation of serum alanine aminotransferase in healthy subjects. Gut $2008 \mathbf{5 7}$ 649-654. (https://doi.org/10.1136/ gut.2007.131797)

72 Chiu S, Sievenpiper JL, de Souza RJ, Cozma AI, Mirrahimi A, Carleton AJ, Ha V, Di Buono M, Jenkins AL, Leiter LA et al. Effect of fructose on markers of non-alcoholic fatty liver disease (NAFLD): a systematic review and meta-analysis of controlled feeding trials. European Journal of Clinical Nutrition 201468 416-423. (https://doi. org/10.1038/ejcn.2014.8)

73 Ajmera V, Belt P, Wilson LA, Gill RM, Loomba R, Kleiner DE, Neuschwander-Tetri BA \& Terrault N. Among patients with nonalcoholic fatty liver disease, modest alcohol use is associated with less improvement in histologic steatosis and steatohepatitis. Clinical Gastroenterology and Hepatology 201816 1511-1520.e5. (https://doi. org/10.1016/j.cgh.2018.01.026)

74 Ryan MC, Itsiopoulos C, Thodis T, Ward G, Trost N, Hofferberth S, O’Dea K, Desmond PV, Johnson NA \& Wilson AM. The Mediterranean diet improves hepatic steatosis and insulin sensitivity in individuals with non-alcoholic fatty liver disease. Journal of Hepatology 201359 138-143. (https://doi.org/10.1016/j. jhep.2013.02.012)

75 Zelber-Sagi S, Salomone F, Webb M, Lotan R, Yeshua H, Halpern Z, Santo E, Oren R \& Shibolet O. Coffee consumption and nonalcoholic fatty liver onset: a prospective study in the general population. Translational Research: Journal of Laboratory and
Clinical Medicine 2015165 428-436. (https://doi.org/10.1016/j. trsl.2014.10.008)

76 Ley RE, Backhed F, Turnbaugh P, Lozupone CA, Knight RD \& Gordon JI. Obesity alters gut microbial ecology. PNAS 2005102 11070-11075. (https://doi.org/10.1073/pnas.0504978102)

77 Ley RE, Turnbaugh PJ, Klein S \& Gordon JI. Microbial ecology: human gut microbes associated with obesity. Nature $2006 \mathbf{4 4 4}$ 1022-1023. (https://doi.org/10.1038/4441022a)

78 Haro C, Montes-Borrego M, Rangel-Zuniga OA, Alcala-Diaz JF, GomezDelgado F, Perez-Martinez P, Delgado-Lista J, Quintana-Navarro GM, Tinahones FJ, Landa BB et al. Two healthy diets modulate gut microbial community improving insulin sensitivity in a human obese population. Journal of Clinical Endocrinology and Metabolism 2016101 233-242. (https://doi.org/10.1210/jc.2015-3351)

79 Munoz-Garach A, Diaz-Perdigones C \& Tinahones FJ. Gut microbiota and type 2 diabetes mellitus. Endocrinologia y Nutricion 201663 560-568. (https://doi.org/10.1016/j.endoen.2016.07.004)

80 Doulberis M, Kotronis G, Gialamprinou D, Kountouras J \& Katsinelos P. Non-alcoholic fatty liver disease: an update with special focus on the role of gut microbiota. Metabolism: Clinical and Experimental $2017 \mathbf{7 1}$ 182-197. (https://doi.org/10.1016/j. metabol.2017.03.013)

81 Wang B, Jiang X, Cao M, Ge J, Bao Q, Tang L, Chen Y \& Li L. Altered fecal microbiota correlates with liver biochemistry in nonobese patients with non-alcoholic fatty liver disease. Scientific Reports 2016 6 32002. (https://doi.org/10.1038/srep32002)

82 Udayappan S, Manneras-Holm L, Chaplin-Scott A, Belzer C, Herrema H, Dallinga-Thie GM, Duncan SH, Stroes ESG, Groen AK, Flint $\mathrm{HJ}$ et al. Oral treatment with Eubacterium hallii improves insulin sensitivity in $\mathrm{db} / \mathrm{db}$ mice. NPJ Biofilms and Microbiomes 2016 2 16009. (https://doi.org/10.1038/npjbiofilms.2016.9)

83 Yuan J, Chen C, Cui J, Lu J, Yan C, Wei X, Zhao X, Li N, Li S, Xue G et al. Fatty liver disease caused by high-alcohol-producing Klebsiella pneumoniae. Cell Metabolism 201930 675-688.e7. (https://doi. org/10.1016/j.cmet.2019.08.018)

84 Wong VW, Won GL, Chim AM, Chu WC, Yeung DK, Li KC \& Chan HL. Treatment of nonalcoholic steatohepatitis with probiotics. A proof-of-concept study. Annals of Hepatology 201312 256-262. (https://doi.org/10.1016/S1665-2681(19)31364-X)

85 Vrieze A, Out C, Fuentes S, Jonker L, Reuling I, Kootte RS, van Nood E, Holleman F, Knaapen M, Romijn JA et al. Impact of oral vancomycin on gut microbiota, bile acid metabolism, and insulin sensitivity. Journal of Hepatology 201460 824-831. (https://doi. org/10.1016/j.jhep.2013.11.034)

86 Lassailly G, Caiazzo R, Buob D, Pigeyre M, Verkindt H, Labreuche J, Raverdy V, Leteurtre E, Dharancy S, Louvet A et al. Bariatric surgery reduces features of nonalcoholic steatohepatitis in morbidly obese patients. Gastroenterology 2015149 379-388. (https://doi. org/10.1053/j.gastro.2015.04.014)

87 Fakhry TK, Mhaskar R, Schwitalla T, Muradova E, Gonzalvo JP \& Murr MM. Bariatric surgery improves nonalcoholic fatty liver disease: a contemporary systematic review and meta-analysis. Surgery for Obesity and Related Diseases 201915 502-511. (https://doi. org/10.1016/j.soard.2018.12.002)

88 Caiazzo R, Lassailly G, Leteurtre E, Baud G, Verkindt H, Raverdy V, Buob D, Pigeyre M, Mathurin P \& Pattou F. Roux-en-Y gastric bypass versus adjustable gastric banding to reduce nonalcoholic fatty liver disease: a 5-year controlled longitudinal study. Annals of Surgery 2014 260 893-898 . (https://doi.org/10.1097/SLA.0000000000000945)

89 Vargas EJ, Rizk M, Bazerbachi F \& Abu Dayyeh BK. Medical devices for obesity treatment: endoscopic bariatric therapies. Medical Clinics of North America 2018102 149-163. (https://doi.org/10.1016/j. mcna.2017.08.013)

90 Abu Dayyeh BK, Bazerbachi F, Graupera I \& Cardenas A. Endoscopic bariatric and metabolic therapies for non-alcoholic fatty liver disease. 
Journal of Hepatology 201971 1246-1248. (https://doi.org/10.1016/j. jhep.2019.07.026)

91 Nguyen V, Li J, Gan J, Cordero P, Ray S, Solis-Cuevas A, Khatib M \& Oben JA. Outcomes following serial intragastric balloon therapy for obesity and nonalcoholic fatty liver disease in a single centre. Canadian Journal of Gastroenterology and Hepatology 20172017 4697194. (https://doi.org/10.1155/2017/4697194)

92 Loomba R, Lutchman G, Kleiner DE, Ricks M, Feld JJ, Borg BB, Modi A, Nagabhyru P, Sumner AE, Liang TJ et al. Clinical trial: pilot study of metformin for the treatment of non-alcoholic steatohepatitis. Alimentary Pharmacology and Therapeutics 200929 172-182. (https://doi.org/10.1111/j.1365-2036.2008.03869.x)

93 Vilar-Gomez E, Vuppalanchi R, Desai AP, Gawrieh S, Ghabril M, Saxena R, Cummings OW \& Chalasani N. Long-term metformin use may improve clinical outcomes in diabetic patients with nonalcoholic steatohepatitis and bridging fibrosis or compensated cirrhosis. Alimentary Pharmacology and Therapeutics 201950 317-328. (https://doi.org/10.1111/apt.15331)

94 Drucker DJ. Mechanisms of action and therapeutic application of glucagon-like peptide-1. Cell Metabolism 201827 740-756. (https:// doi.org/10.1016/j.cmet.2018.03.001)

95 Armstrong MJ, Gaunt P, Aithal GP, Barton D, Hull D, Parker R, Hazlehurst JM, Guo K, Abouda G, Aldersley MA et al. Liraglutide safety and efficacy in patients with non-alcoholic steatohepatitis (LEAN): a multicentre, double-blind, randomised, placebo-controlled phase 2 study. Lancet 2016387 679-690. (https://doi.org/10.1016/ S0140-6736(15)00803-X)

96 Marso SP, Daniels GH, Brown-Frandsen K, Kristensen P, Mann JFE, Nauck MA, Nissen SE, Pocock S, Poulter NR, Ravn LS et al. Liraglutide and cardiovascular outcomes in type 2 diabetes. New England Journal of Medicine 2016375 311-322. (https://doi.org/10.1056/ NEJMoa1603827)

97 National Institutes of Health Clinical Center (CC) NIoDaDaKDN Non-Alcoholic Fatty Liver Disease, the HEpatic Response to Oral Glucose, and the Effect of Semaglutide (NAFLD HEROES), 2019 [updated 26 July 2019]. (available at: https://clinicaltrials.gov/ct2/ show/NCT03884075)

98 Scheen AJ. Beneficial effects of SGLT2 inhibitors on fatty liver in type 2 diabetes: a common comorbidity associated with severe complications. Diabetes Metabolism 201945 213-223. (https://doi. org/10.1016/j.diabet.2019.01.008)

99 Hayashizaki-Someya Y, Kurosaki E, Takasu T, Mitori H, Yamazaki S, Koide K \& Takakura S. Ipragliflozin, an SGLT2 inhibitor, exhibits a prophylactic effect on hepatic steatosis and fibrosis induced by choline-deficient l-amino acid-defined diet in rats. European Journal of Pharmacology 2015 754:19-24. (https://doi.org/10.1016/j. ejphar.2015.02.009)

100 Neal B, Perkovic V, Mahaffey KW, de Zeeuw D, Fulcher G, Erondu N, Shaw W, Law G, Desai M \& Matthews DR. Canagliflozin and cardiovascular and renal events in type 2 diabetes. New England Journal of Medicine 2017377 644-657. (https://doi.org/10.1056/ NEJMoa1611925)

101 Cusi K, Orsak B, Bril F, Lomonaco R, Hecht J, Ortiz-Lopez C, Tio F, Hardies J, Darland C, Musi N et al. Long-term pioglitazone treatment for patients with nonalcoholic steatohepatitis and prediabetes or type 2 diabetes mellitus: a randomized trial. Annals of Internal Medicine 2016165 305-315. (https://doi.org/10.7326/M151774)

102 Ratziu V, Giral P, Jacqueminet S, Charlotte F, Hartemann-Heurtier A, Serfaty L, Podevin P, Lacorte JM, Bernhardt C, Bruckert E et al. Rosiglitazone for nonalcoholic steatohepatitis: one-year results of the randomized placebo-controlled Fatty Liver Improvement with Rosiglitazone Therapy (FLIRT) trial. Gastroenterology 2008135 100-110. (https://doi.org/10.1053/j.gastro.2008.03.078)

103 Sanyal AJ, Chalasani N, Kowdley KV, McCullough A, Diehl AM, Bass NM, Neuschwander-Tetri BA, Lavine JE, Tonascia J, Unalp A et al. Pioglitazone, vitamin E, or placebo for nonalcoholic steatohepatitis. New England Journal of Medicine 2010362 1675-1685. (https://doi.org/10.1056/NEJMoa0907929)

104 Tuccori M, Filion KB, Yin H, Yu OH, Platt RW \& Azoulay L. Pioglitazone use and risk of bladder cancer: population based cohort study. BMJ 2016352 i1541. (https://doi.org/10.1136/bmj.i1541)

105 Gilead. Gilead Announces Topline Data From Phase 3 STELLAR-4 Study of Selonsertib in Compensated Cirrhosis (F4) Due to Nonalcoholic Steatohepatitis (NASH), 2019 [updated 11 February 2019]. (available at: https://www.gilead.com/news-and-press/ press-room/press-releases/2019/2/gilead-announces-topline-datafrom-phase-3-stellar4-study-of-selonsertib-in-compensated-cirrhosisf4-due-to-nonalcoholic-steatohepatitis-nash)

106 Gilead. Gilead Announces Topline Data From Phase 3 STELLAR-3 Study of Selonsertib in Bridging Fibrosis (F3) Due to Nonalcoholic Steatohepatitis (NASH), 2019 [updated 25 April 2019]. (available at: https://www.gilead.com/news-and-press/press-room/ press-releases/2019/4/gilead-announces-topline-data-fromphase-3-stellar3-study-of-selonsertib-in-bridging-fibrosis-f3-due-tononalcoholic-steatohepatitis-nash)

107 Friedman SL, Ratziu V, Harrison SA, Abdelmalek MF, Aithal GP, Caballeria J, Francque S, Farrell G, Kowdley KV, Craxi A et al. A randomized, placebo-controlled trial of cenicriviroc for treatment of nonalcoholic steatohepatitis with fibrosis. Hepatology 201867 1754-1767. (https://doi.org/10.1002/hep.29477)

108 Ratziu V, Sanyal A, Harrison SA, Wong VW, Francque S, Goodman Z, Aithal GP, Kowdley KV, Seyedkazemi S, Fischer L et al. Cenicriviroc treatment for adults with nonalcoholic steatohepatitis and fibrosis: final analysis of the phase 2b CENTAUR study. Hepatology 2020 In press. (https://doi.org/10.1002/hep.31108)

109 Schürks M, Glynn RJ, Rist PM, Tzourio C \& Kurth T. Effects of vitamin $\mathrm{E}$ on stroke subtypes: meta-analysis of randomised controlled trials. BMJ 2010341 c5702. (https://doi.org/10.1136/bmj. c5702)

110 Klein EA, Thompson IM, Jr., Tangen CM, Crowley JJ, Lucia MS, Goodman PJ, Minasian LM, Ford LG, Parnes HL, Gaziano JM et al. Vitamin $\mathrm{E}$ and the risk of prostate cancer: the Selenium and Vitamin E Cancer Prevention Trial (SELECT). JAMA 2011306 1549-1556. (https://doi.org/10.1001/jama.2011.1437)

111 Eslami L, Merat S, Malekzadeh R, Nasseri-Moghaddam S \& Aramin H. Statins for non-alcoholic fatty liver disease and non-alcoholic steatohepatitis. Cochrane Database of Systematic Reviews 2013 Cd008623. (https://doi.org/10.1002/14651858.CD008623.pub2)

112 Sinha RA, Singh BK \& Yen PM. Direct effects of thyroid hormones on hepatic lipid metabolism. Nature Reviews Endocrinology $2018 \mathbf{1 4}$ 259-269. (https://doi.org/10.1038/nrendo.2018.10)

113 Bruinstroop E, Dalan R, Cao Y, Bee YM, Chandran K, Cho LW, Soh SB, Teo EK, Toh SA, Leow MKS et al. Low-dose levothyroxine reduces intrahepatic lipid content in patients with type 2 diabetes mellitus and NAFLD. Journal of Clinical Endocrinology and Metabolism 2018103 2698-2706. (https://doi.org/10.1210/jc.2018-00475)

114 Harrison SA, Bashir MR, Guy CD, Zhou R, Moylan CA, Frias JP, Alkhouri N, Bansal MB, Baum S, Neuschwander-Tetri BA et al. Resmetirom (MGL-3196) for the treatment of non-alcoholic steatohepatitis: a multicentre, randomised, double-blind, placebocontrolled, phase 2 trial. Lancet 2019394 2012-2024. (https://doi. org/10.1016/S0140-6736(19)32517-6)

115 Madrigal Pharmaceuticals I. A phase 3 study to evaluate the efficacy and safety of MGL-3196 (resmetirom) in patients with NASH and fibrosis (MAESTRO-NASH), 2019 [updated 17 July 2019]. (available at: https://clinicaltrials.gov/ct2/show/NCT03900429)

116 de Aguiar Vallim TQ, Tarling EJ \& Edwards PA. Pleiotropic roles of bile acids in metabolism. Cell Metabolism 201317 657-669. (https:// doi.org/10.1016/j.cmet.2013.03.013)

117 Pharmaceuticals I. Randomized global phase 3 study to evaluate the impact on NASH with fibrosis of obeticholic acid treatment 
(REGENERATE), 2019 [updated 31 January 2019]. (available at: https://clinicaltrials.gov/ct2/show/NCT02548351)

118 Pharmaceuticals N. Study of safety and efficacy of tropifexor (LJN452) in patients with non-alcoholic Steatohepatitis (NASH) FLIGHT-FXR, 2019. (available at: https://clinicaltrials.gov/ct2/show/ NCT02855164?term=FXR\&cond=NASH\&rank=2)

119 Pharma E. Safety, tolerability, pharmacokinetics and pharmacodynamics of EYP001a in healthy volunteers and nonalcoholic steatohepatitis patients 2019 (available at: https:// clinicaltrials.gov/ct2/show/NCT03976687?term=FXR\&cond=NASH\&r ank=3)

120 Karim F. Role of obeticholic acid in the patients of NAFLD with raised ALT (NAFLD), 2019. (available at: https://clinicaltrials.gov/ct2/show/ NCT03836937?term=FXR\&cond=NASH\&rank=7)

121 Albireo. A phase 2 study of elobixibat in adults with NAFLD or NASH, 2019. (available at: https://clinicaltrials.gov/ct2/show/NCT04 006145?term=bile+acid\&cond=NAFLD\&draw $=2 \&$ rank $=5$ )

122 Ltd HBP. A study of HTD1801 in adults with nonalcoholic steatohepatitis (NASH) and type 2 diabetes mellitus (T2DM), 2019. (available at: https://clinicaltrials.gov/ct2/show/NCT03656744?term= bile+acid\&cond=NAFLD\&draw $=2 \&$ rank $=19$ )

123 Lindor KD, Kowdley KV, Heathcote EJ, Harrison ME, Jorgensen R, Angulo P, Lymp JF, Burgart L \& Colin P. Ursodeoxycholic acid for treatment of nonalcoholic steatohepatitis: results of a randomized trial. Hepatology 200439 770-778. (https://doi.org/10.1002/ hep.20092)

124 Neuschwander-Tetri BA, Loomba R, Sanyal AJ, Lavine JE, Van Natta ML, Abdelmalek MF, Chalasani N, Dasarathy S, Diehl AM, Hameed B et al. Farnesoid X nuclear receptor ligand obeticholic acid for non-cirrhotic, non-alcoholic steatohepatitis (FLINT): a multicentre, randomised, placebo-controlled trial. Lancet 2015385 956-965. (https://doi.org/10.1016/S0140-6736(14)61933-4)

125 Younossi ZM, Ratziu V, Loomba R, Rinella M, Anstee QM, Goodman Z, Bedossa P, Geier A, Beckebaum S, Newsome PN et al. Obeticholic acid for the treatment of non-alcoholic steatohepatitis: interim analysis from a multicentre, randomised, placebo-controlled phase 3 trial. Lancet 2019394 2184-2196. (https://doi.org/10.1016/ S0140-6736(19)33041-7)

126 Pharmaceuticals N. Safety, tolerability, and efficacy of a combination treatment of tropifexor (LJN452) and cenicriviroc (CVC) in adult patients with nonalcoholic steatohepatitis (NASH) and Liver fibrosis. TANDEM 2019. (available at: https://clinicaltrials.gov/ct2/show/NCT 03517540 ?term $=$ TANDEM\&rank $=8$ )

127 Sciences G. Safety and efficacy of selonsertib, firsocostat, cilofexor, and combinations in participants with bridging fibrosis or compensated cirrhosis due to nonalcoholic steatohepatitis (NASH) (ATLAS), 2018 [updated 24 May 2019]. (available at: https:// clinicaltrials.gov/ct2/show/NCT03449446)

128 Pockros PJ, Fuchs M, Freilich B, Schiff E, Kohli A, Lawitz EJ, Hellstern PA, Owens-Grillo J, Van Biene C, Shringarpure R et al. CONTROL: a randomized phase 2 study of obeticholic acid and atorvastatin on lipoproteins in nonalcoholic steatohepatitis patients. Liver International 201939 2082-2093. (https://doi.org/10.1111/liv.14209)

129 NHG. NHG-standard viral hepatitis and other liver diseases (third revision). Liver International 201939 2082-2093. (https://doi. org/10.1111/liv.14209)
130 Francque S, Lanthier N, Verbeke L, Reynaert H, Van Steenkiste C, Vonghia L, Kwanten WJ, Weyler J, Trepo E, Cassiman D et al. The Belgian association for study of the liver guidance document on the management of adult and paediatric non-alcoholic fatty liver disease. Acta gastro-enterologica Belgica $2018 \mathbf{8 1} 55-81$.

131 Draijer LG, Feddouli S, Bohte AE, Vd Baan Slootweg O, Pels Rijcken TH, Benninga MA, Stoker J, Koot BGP. Comparison of diagnostic accuracy of screening tests ALT and ultrasound for pediatric non-alcoholic fatty liver disease. European Journal of Pediatrics 2019178 863-870. (https://doi.org/10.1007/s00431-01903362-3)

132 Musso G, Gambino R, Cassader M, Pagano G. Meta-analysis: natural history of non-alcoholic fatty liver disease (NAFLD) and diagnostic accuracy of non-invasive tests for liver disease severity. Annals of Medicine 201143 617-649. (https://doi.org/10.3109/07853890.2010. 518623)

133 Takeuchi H, Sugimoto K, Oshiro H, Iwatsuka K, Kono S, Yoshimasu Y, Kasai Y, Furuichi Y, Sakamaki K, Itoi T. Liver fibrosis: noninvasive assessment using supersonic shear imaging and FIB4 index in patients with non-alcoholic fatty liver disease. Journal of Medical Ultrasonics 201845 243-249. (https://doi.org/10.1007/s10396-0170840-3)

134 Soto M, Sampietro-Colom L, Lasalvia L, Mira A, Jimenez W, Navasa M. Cost-effectiveness of enhanced liver fibrosis test to assess liver fibrosis in chronic hepatitis $\mathrm{C}$ virus and alcoholic liver disease patients. World J Gastroenterol. 201723 3163-3173. (https://doi. org/10.3748/wjg.v23.i17.3163)

135 Xie Q, Zhou X, Huang P, Wei J, Wang W, Zheng S. The performance of enhanced liver fibrosis (ELF) test for the staging of liver fibrosis: a meta-analysis. PLoS ONE 20149 e92772. (https://doi.org/10.1371/ journal.pone.0092772)

136 Passanten prijslijst DBC-zorgproducten en overige zorgproducten jaar 2020 - LUMC - Ingangsdatum 1-jan-2020, 2020 [updated 04-022020; cited 2020 23-03]. (available at: https://www.lumc.nl/pat/ att/14050711503857/Passantenlijst-DBC-2020)

137 Rockey DC, Caldwell SH, Goodman ZD, Nelson RC, Smith AD. Liver Biopsy. Hepatology 200949 1017-1044. (https://doi.org/10.1002/ hep.22742)

138 Tarievenlijst kalenderjaar 2019 onderlinge dienstverlening UMCG 2019 [cited 2020 23-03]. (available at: https://www.umcg.nl/ SiteCollectionDocuments/Zorg/Verwijzers/umcg-onderlingedienstverlening-2019.pdf)

139 Kamali L, Adibi A, Ebrahimian S, Jafari F, Sharifi M. Diagnostic performance of ultrasonography in detecting fatty liver disease in comparison with fibroscan in people suspected of fatty liver. Advanced Biomedical Research 20198 69. (https://doi.org/10.4103/abr. abr_114_19)

140 Meng F, Zheng Y, Zhang Q, Mu X, Xu X, Zhang H, Ding L. Noninvasive evaluation of liver fibrosis using real-time tissue elastography and transient elastography (FibroScan). Journal of Ultrasound in Medicine 201534 403-410. (https://doi.org/10.7863/ ultra.34.3.403)

141 Kim M, Kang BK, Jun DW. Comparison of conventional sonographic signs and magnetic resonance imaging proton density fat fraction for assessment of hepatic steatosis. Scientific Reports $2018 \mathbf{8} 7759$. (https://doi.org/10.1038/s41598-018-26019-x)

Received 22 January 2020

Revised version received 1 April 2020

Accepted 4 June 2020 